SANDIA REPORT

SAND97-2395 • UC-704

Unlimited Release

Printed October 1997

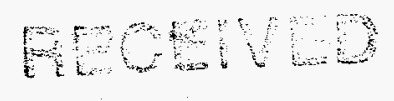

10V $2: 1997$

OST

\title{
Modeling and Characterization of Molecular Structures in Self Assembled and Langmuir - Blodgett Films for Controlled Fabrication
}

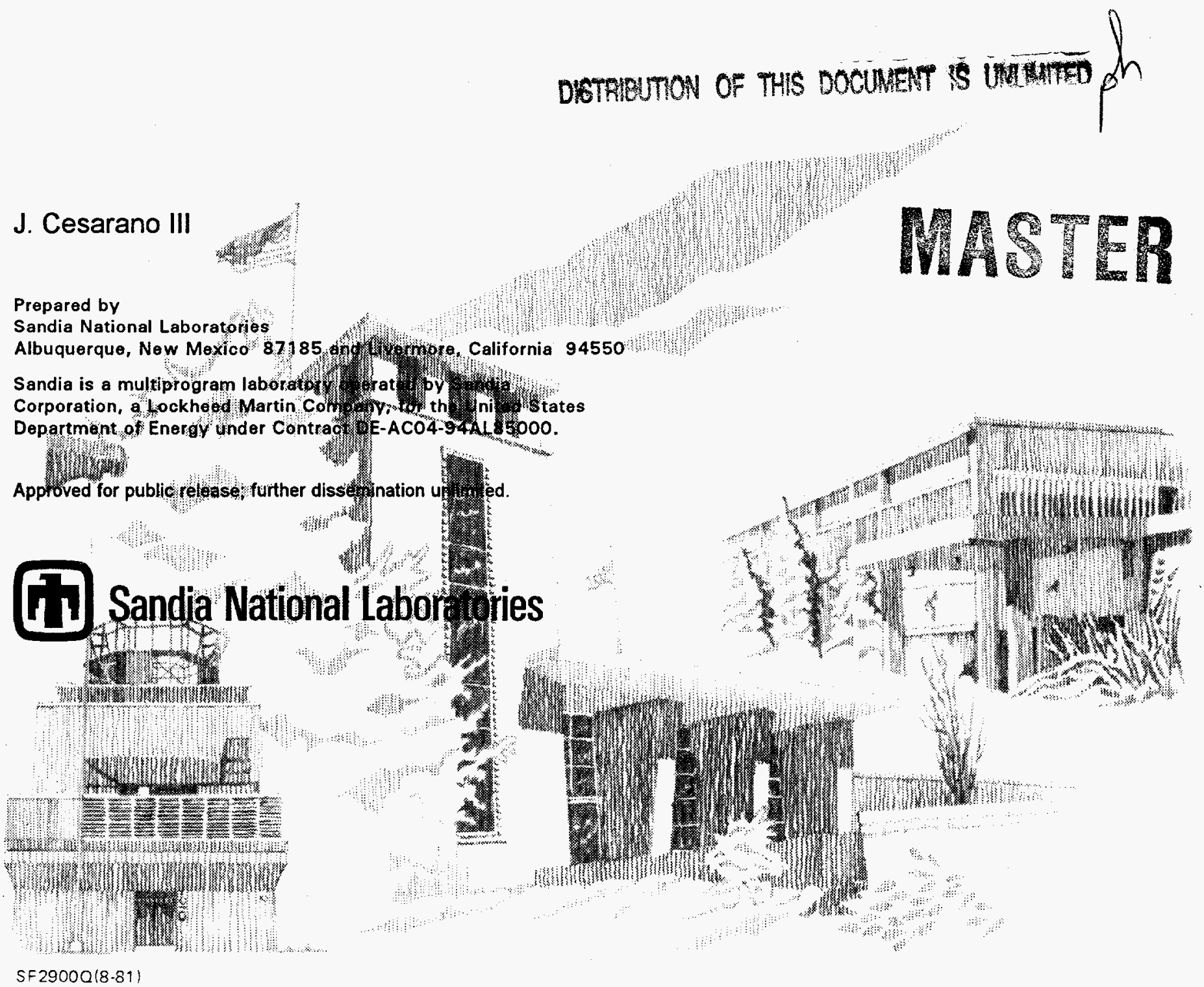


Issued by Sandia National Laboratories, operated for the United States Department of Energy by Sandia Corporation.

NOTICE: This report was prepared as an account of work sponsored by an agency of the United States Government. Neither the United States Government nor any agency thereof, nor any of their employees, nor any of their contractors, subcontractors, or their employees, makes any warranty, express or implied, or assumes any legal liability or responsibility for the accuracy, completeness, or usefulness of any information, apparatus, product, or process disclosed, or represents that its use would not infringe privately owned rights. Reference herein to any specific commercial product, process, or service by trade name, trademark, manufacturer, or otherwise, does not necessarily constitute or imply its endorsement, recommendation, or favoring by the United States Government, any agency thereof, or any of their contractors or subcontractors. The views and opinions expressed herein do not necessarily state or reflect those of the United States Government, any agency thereof, or any of their contractors.

Printed in the United States of America. This report has been reproduced directly from the best available copy.

Available to DOE and DOE contractors from

Office of Scientific and Technical Information

P.O. Box 62

Oak Ridge, TN 37831

Prices available from (615) 576-8401, FTS 626-8401

Available to the public from

National Technical Information Service

U.S. Department of Commerce

5285 Port Royal Rd

Springfield, VA 22161

NTIS price codes

Printed copy: A03

Microfiche copy: A01 


\section{DISCLAMMER}

Portions of this document may be illegible in electronic image products. Images are produced from the best available original document. 
SAND 97-2395

Unlimited Release

Printed October 1997

\author{
Distribution \\ Category UC-704
}

\title{
Modeling and Characterization of Molecular Structures in Self Assembled and Langmuir - Blodgett Films for Controlled Fabrication
}

\author{
J. Cesarano III \\ Materials and Process Sciences Center \\ Sandia National Laboratories \\ P. O. Box 5800 \\ Albuquerque, NM 87185-1349
}

\begin{abstract}
Self Assembled (SA) thin films and Langmuir - Blodgett (LB) thin films are emerging technologies for the development of chemical and bio-chemical sensors, electrooptic films, second harmonic generators (frequency doublers), templates for biomimetic growth etc.. However, the growth of these technologies is dependent on the development of our understanding and control of the molecular arrangement of these films. This is not trivial since SA and LB films are essentially two-dimensional monolayer structures. One of the goals of this project was to extend Sandia's characterization techniques and molecular modeling capabilities for these complex twodimensional geometries with the objective of improving our control of the fabrication of these structures for specific applications. Achieving this requires understanding both the structure throughout the thickness of the films and the in-plane lattice of the amphiphilic molecules. To meet these objectives we used atomic force microscopy (AFM), X-ray reflectivity, and molecular modeling.

While developing these capabilities, three different materials systems were fabricated and characterized: 1) Self Assembled Monolayers (SAMs) of octadecyltrichlorosilane (OTS) and LB films of arachidic acid on silicon wafers; 2) SAMs on PZT substrates; and 3) electrochemical deposition of CdS on LB film templates. The SAMs and LB films deposited on silicon were characterized using characterized using $\mathrm{x}$-ray reflectivity. This technique proved to be useful for understanding the molecularly layered structure in the direction perpendicular to the substrate (see Appendix C). The study of SAMs on PZT was a novel study. The self assembly of OTS has been demonstrated and studied on silica surfaces however, in this work we demonstrated SAM formation on PZT, determined the mechanism for SAM formation on PZT, and demonstrated that SAMs on PZT can modify the surface behavior. These results are discussed in detail in Appendix A and imply that SAMs may be useful for micropatterning of PZT and development of next generation optics-based microelectronics. In Appendix B there is a detailed discussion about using LB films and electrochemistry to create template assisted growth of thin films of CdS. In this work atomic force microscopy was used to characterized the in-plane structure of LB films and to study how the chemical functionality of LB films can effect the growth of CdS.
\end{abstract}




\section{SUMMARY}

Self assembled and Langmuir - Blodgett films have been the focus of intense investigation in recent years. This results from the plethora of possible applications for these unique two-dimensional structures. Applications include chemical and biochemical sensors, electrooptic films, second harmonic generators (frequency doublers), and templates for biomimetic growth. However, wide spread use of these films is limited because characterization and control of their two-dimensional geometries has proven evasive. The goal of this research project was to develop a capability for the molecular level characterization, modeling and fabrication of SA and LB films for possible applications in the previously mentioned areas. A farther term objective is to use these new capabilities to improve our control of the fabrication of thin films for specific applications.

The project was completed within three different materials systems and is discussed in detail in Appendices A-C. The project was successful in developing capabilities for fabrication and characterization of self assembled thin film structures in general. However, extensive modeling of the structures proved evasive and is not discussed in detail. The most interesting characterization was completed using atomic force microscopy (AFM) and x-ray reflectivity. The AFM can be used to study local features rather than relying on data averaged over large areas to provide information of molecular ordering. This allows the study of the in-plane structure such as local ordering, defect structures, as well as grain boundaries. X-ray reflectivity can provide detailed structural information throughout the thickness of these films.

Appendix A discusses the formation, characterization, and utility of OTS SAMs on PZT substrates. This is a novel development. Appendix B discusses the fabrication and characterization of CdS thin films that were formed by using LB film templated (i.e., biomimetic) growth in the presence of electric fields. This is another novel development. Finally, the utility of $x$-ray reflectivity for studying the out-of-plane structure of SAMs and LB films is demonstrated in Appendix C for films deposited on silicon wafers.

In general, the SAMs studied were octadecyltrichlorosilane on silica and hexadecyl mercaptan on gold. The LB films were cadmium arachidate. The following pages highlight the fabrication procedures for the LB films. More detail is provided in the appendices. 


\section{Table of Contents}

Title

1

Abstract

Summary

2

Table of Contents

Lamgmuir-Blodgett Film Fabrication
Appendix A:- Reprint-pulled for sepanate processing on Thin Films of Lead Zirconate Titanate (PZT)

B - 1

Appendix B: Template-Assisted Electrochemical Deposition of

Ultrathin Films of Cadmium Sulfide

Appendix C: Characterization of Langmuir - Blodgett Films

C -1

Using X-ray Reflectivity 


\section{Langmuir Blodgett Films are Highly Ordered Films}

- Langmuir-Blodgett films are monolayers or multilayers transferred from the water-air interface onto a solid substrate
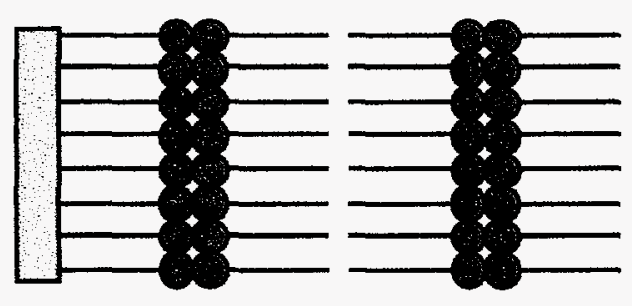

1

\section{Langmuir Films}
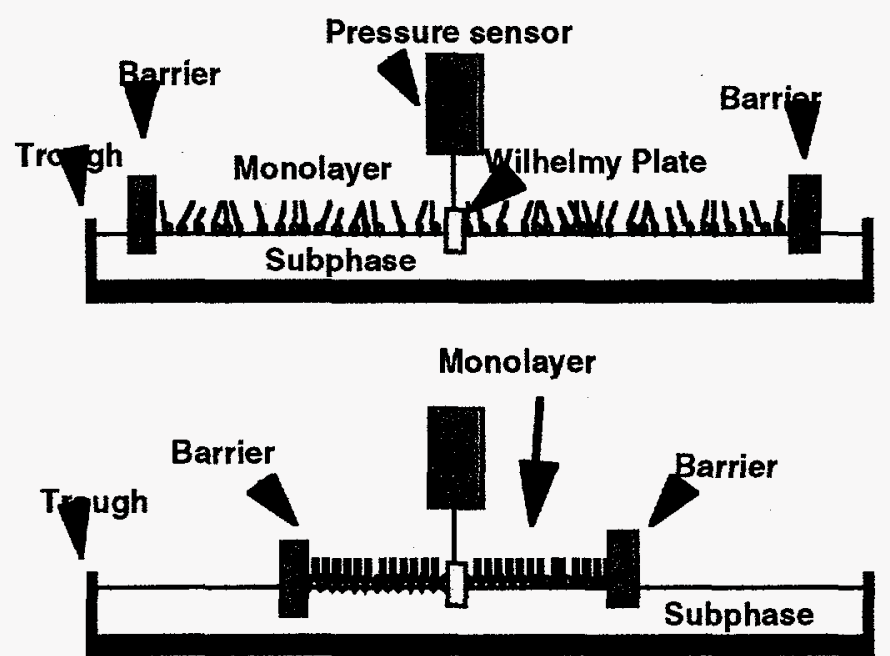


\section{LB films Deposited as Substrate Passes}

Air-water Interface

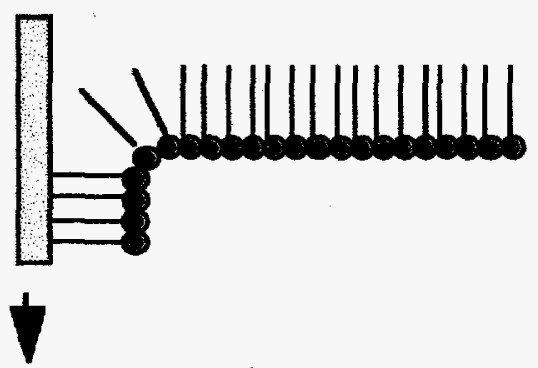

- Hydrophobic substrates begin deposition on first downward pass (Hydrophilic substrates start on first upward pass)

- Hydrophobic tail groups contact substrate and are deposited

- With hydrophilic substrates, head groups are deposited

- Multilayers are built up "head-to-head and tail-to-tail"

\section{Arachidic Acid Used as Deposition Material}

- Is an amphiphilic molecule

- Will form ideal LB films<smiles>CCCCCCCCCCCCCCCCCCCC(=O)O</smiles>

Arachidic Acid

$\mathrm{CH}_{3}-\left(\mathrm{CH}_{2}\right)_{18}-\mathrm{COOH}$ 


\section{Subphase $\mathrm{pH}$ and Cadmium}

Concentration Control Rigidity of LB Film

- Higher pH and concentration of $\mathrm{Cd}^{+2}$ ions in subphase form more rigid monolayers

- Less acidic pH promotes dissociation of carboxylic group

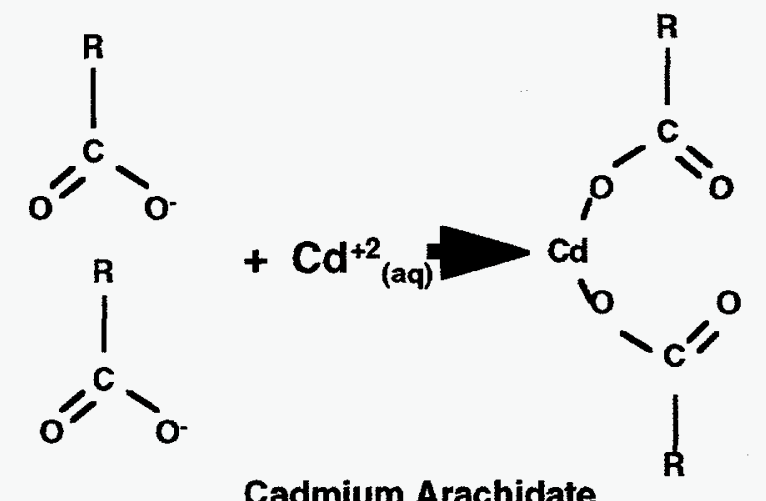

Cadmium Arachidate

\section{Substrates Treated to Form Hydrophobic Surface}

- Silicon wafers and PZT substrates treated with Octadecyltrichlorosilane(OTS),

- Methyl terminated chain makes substrate surface hydrophobic

- Hexadecyl Mercaptan, $\mathrm{HS}$ - $\left(\mathrm{CH}{ }_{2}\right)_{15}-\mathrm{CH}_{3}$, reacts in a similar way with gold coated wafers 


\section{Chemical Functionality of 4 and 5}

layer LB Fllms

- Four layer films have the methyl group outward
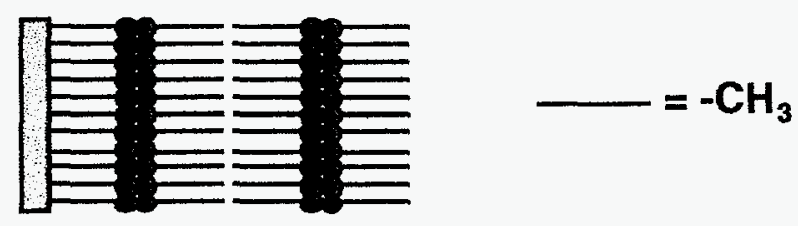

- Five layer films have carboxylic acid group outward

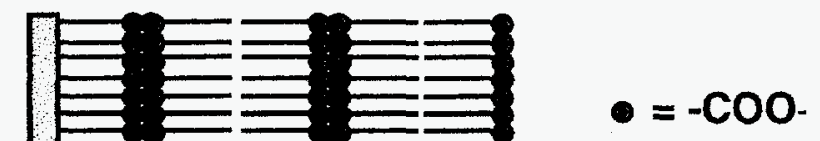

7

\section{Conditions Used for Biomimetic} Templating

- Biomimetic template processing imitates the deposition of

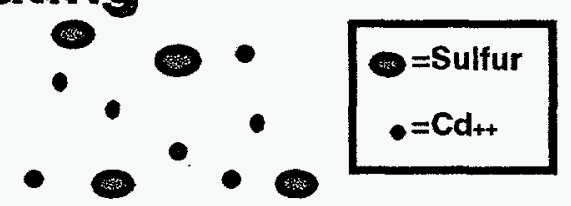
inorganics on an organic layer

- Previous trials led to the following conditions:

$-\mathrm{pH}: 6.5$

$-\left[\mathrm{Cd}^{+2}\right]: 5 \times 10^{-4} \mathrm{M}$

Langmuir Blodgett film

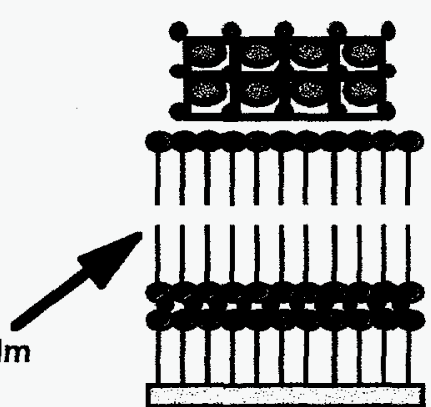




\title{
APPENDIX B
}

\section{Template-Assisted Electrochemical Deposition of Ultrathin Films of Cadmium Sulfide}

\author{
Joseph Cesarano III, ${ }^{*}$ Xiang Xu, ${ }^{\ddagger}$ Eileen Burch, ${ }^{\dagger}$ and Gabriel P. Lopez ${ }^{\ddagger *}$ \\ $\dagger$ Dept. 1831, Sandia National Laboratories, Albuquerque, NM and \\ $\ddagger$ Dept. of Chemical \& Nuclear Engineering, University of New Mexico, Albuquerque, NM
}

\begin{abstract}
Uniform thin films of cadmium sulfide were prepared by template-assisted electrochemical deposition on gold electrodes covered with Langmuir-Blodgett (LB) films. An electrolytic cell was used for the production of low concentrations of $S^{-}$to effect heterogeneous crystallization on LB films, while preventing homogeneous precipitation. 3,4 and 5 layer LB films of cadmium arachidate were investigated. Charcterization of deposited films by optical microscopy, atomic force microscopy and energy dispersive $\mathrm{X}$ ray analysis of film composition indicated that a variety of different types of CdS films can be produced depending on the type of LB film used, the electrode at which templateassisted deposition is carried out, the magnitude and frequency of alternating potentials used, and the deposition time used. In general, hydrophilic organic films that present cadmium carboxylate groups to the deposition surface (i.e., 3 and 5 layer LB films) supported crystallization of CdS, while those that present hydrophobic, methyl groups (i.e., 4 layer LB films and self-assembled monolayers of alkanethiolates on gold) did not. The best methods for the rapid deposition of conformal, ultrathin films $(<100 \mathrm{~nm})$ of CdS used highly-ordered 5 layer LB films at grounded electrodes. The data presented suggest that templating with LB films, when used together with electrochemical deposition, has potential for the convenient production of oriented crystalline thin films of cadmium sulfide and similar materials.
\end{abstract}

\section{Introduction}

Thin, conformal, crystalline films of cadmium sulfide (CdS), a II-IV semiconductor compound, are of interest as functional components in a variety of opto-electronic devices such as solid state lasers and detectors,[1] solar cells,[2,3,4] and optical memories.[2] Methods for generating these films have included chemical vapor deposition, [5] plasma sputtering,[6] electrodeposition,[7] and precipitation. $[2,3,4]$ Techniques for preparing films based on heterogeneous crystallization from liquid solutions have several potential 
advantages over vapor phase deposition techniques including the ability to form crystalline films at low temperature over large area substrates. The ability of organic functional groups to facilitate and mediate heterogeneous nucleation from aqueous solutions at solid substrate $[8,9]$ also has the potential to enhance uniform nucleation (crystallite type, orientation and distribution) of CdS and thus lead to superior performance of thin films in device applications. For example, Langmuir-Blodgett (LB) films have been investigated extensively for the controlled nucleation of CdS and have been demonstrated to be useful for the formation of nanoparticles of CdS. One particularly effective methodology for the formation of planar arrays of Q-state particles of CdS has been the exposure of LB films comprised of cadmium arachidate layers to gaseous $\mathrm{H}_{2} \mathrm{~S} .[10,11,12]$

We have examined several methods for template-directed heterogeneous crystallization of CdS and present here a report of preliminary work on a new technique that has produced uniform thin films of CdS through relatively short deposition times. The technique is an extension of that described by Fatas $e t$ al. [7] for the in situ generation of low concentrations of $\mathrm{Cd}^{2+}$ and $\mathrm{S}^{2-}$ by alternating current electrolysis and the subsequent formation of thin CdS films from these precursors. We have examined the effectiveness of several schemes for improving the quality of thin films produced by this technique by the use of template-directed nucleation at the surface of various types of LB films. LB films were prepared by several methods by dipping of gold-coated silicon wafers that had been rendered hydrophobic by the formation of self-assembled monolayers (SAMs) by reaction of the gold surface with $\mathrm{HS}\left(\mathrm{CH}_{2}\right)_{15} \mathrm{CH}_{3}$.[13,14] The primary characterization techniques we have employed thus far in our studies (atomic force microscopy, optical microscopy and energy dispersive $\mathrm{X}$-ray analysis of film composition) suggest that when combined with in situ electrochemical generation of ionic precursors for CdS, organic template-assisted heterogeneous precipitation of $\mathrm{CdS}$ at electrode surfaces is a simple, quick method of generating thin films of CdS in which deposition is restricted primarily to areas of the electrode surface modified with organic template moieties.

\section{Experimental}

\subsection{Materials}

Chemicals used were arachidic acid (Aldrich Chemical Co., Milwaukee WI), hexadecyl mercaptan (Sigma, St. Louis MO), cadmium chloride (Aldrich), sodium bicarbonate (Fisher, Pittsburgh PA), sodium chloride (J.T. Baker, Phillipsburg NJ), sodium thiosulfate 5-hydrate (J.T. Baker), ammonium sulfate (J.T. Baker), and cadmium sulfate (J.T. Baker). All chemicals were used as received. Silicon wafers (100) (MEMC Electronic Materials Inc., Malaysia) were used as substrates for the gold films. Gold films (600 to 1000 $\AA$ ) were deposited by thermal evaporation of gold (99.999\%, Academy Precision Materials, Albuquerque NM) under vacuum onto silicon wafers that had previously been coated with 
an adhesion promoter ( $50 \AA$ of chromium). Samples for use in LB film deposition were treated with dilute ethanolic solutions $(1 \mathrm{mM})$ of hexadecyl mercaptan to form a hydrophobic self-assembled monolayer. A platinum film $(-1000 \AA)$ on a silicon wafer was used as a counter electrode in electrochemical generation of $\mathrm{CdS}$ precursors.

\subsection{Langmuir-Blodgett Films}

The Langmuir-Blodgett films of cadmium arachidate were deposited from a Nima 2011 Langmuir trough. For the 3-layer and 4-layer LB films, the subphase was prepared by adding cadmium chloride to deionized water $(18.2 \mathrm{M} \Omega / \mathrm{cm})$ such that the final concentration of cadmium was $1 \times 10^{-4} \mathrm{M}$. The $\mathrm{pH}$ of the subphase thus prepared was 5.5 and was not further adjusted. To obtain more uniform templating surfaces (see Results and Discussion), 5-layer LB films were also investigated. For 5 layer LB films, the subphase cadmium concentration was $2.5 \times 10^{-4} \mathrm{M}$ and the $\mathrm{pH}$ of the subphase was adjusted to $6.5-7.0$ by addition of $0.1 \mathrm{M} \mathrm{NaHCO}$ solution. For all depositions, the barrier speed was set to 50 $\mathrm{cm} 2 / \mathrm{min}$ for compression and the deposition pressure was $30 \mathrm{mN} / \mathrm{m}$. The upward and downward dipping speeds of the hydrophobic substrate were $1.6 \mathrm{~mm} / \mathrm{min}$.

LB films comprised of 3,4 and 5 layers of $\mathrm{Cd}$-arachidate were investigated. The 4 layer LB film had a hydrophobic outer surface and was transferred from the LB trough to the deposition solution directly. The 3 and 5 layer LB films had hydrophilic surfaces and thus were not stable when exposed to air.[13] We therefore transferred the substrate under water (in a small beaker) from the LB trough to the deposition solution.

\subsection{Deposition of Cadmium Sulfide}

CdS deposition solutions were made according to the method of Fatas, et al. Solutions A and B were mixed in a 1:3 ratio by volume.[7] Solution A consisted of $0.01 \mathrm{M}$ $\mathrm{CdSO}_{4}$ and $0.17 \mathrm{M}\left(\mathrm{NH}_{4}\right)_{2} \mathrm{SO}_{4}$ in deionized water and solution $\mathrm{B}$ consisted of $0.35 \mathrm{M}$ $\mathrm{Na}_{2} \mathrm{~S}_{2} \mathrm{O}_{3}$ and $0.75 \mathrm{M} \mathrm{NaCl}$ in deionized water. Each solution was stirred for approximately 5-10 minutes until the solids were completely dissolved. CdS deposition solutions were prepared by combining the two solutions $\mathrm{A}$ and $\mathrm{B}$ and stirring for at least 10 minutes. When solution $B$ was mixed with solution $A$, the $S_{2} \mathrm{O}_{3}{ }^{2-}$ ions produced $S$ by the disproportionation reaction:[7]

$$
\mathrm{S}_{2} \mathrm{O}_{3}^{2-} \Leftrightarrow \mathrm{S}+\mathrm{SO}_{3}{ }^{2-}
$$

During the film deposition under reducing potentials, $S$ was reduced to $S^{2-}$ by the following reaction:

$$
\mathrm{S}+2 e^{-} \rightarrow \mathrm{S}^{2-}
$$


A potentiostat (EG\&G, Princeton Applied Research Model 173) was used to produce alternating positive and negative square wave potentials on either the electrode coated with the LB film or on the uncoated electrode relative to a ground electrode. The reference electrode was combined with the counter electrode from the potentiostat to form the "charged" electrode which was subjected to the voltage cycles relative to the working ("ground") electrode. For all depositions, the same solution concentrations were used (as described above) and the duration in the voltage cycle of the positive voltage was $2 \mathrm{~s}$, while that of the negative voltage was $1 \mathrm{~s}$. Several potentials (positive and negative) and deposition times were examined. The optimized deposition conditions are reported herein.

For the depositions onto 3- and 4-layer LB films, the ground electrode was a bare platinum film, while the charged electrode was the gold film covered with the SAM and the LB film. In these depositions reduction of $\mathbf{S}$ to $\mathbf{S}^{2-}$ thus occurred at the gold electrode (presumably at defect sites in the SAM covering the electrode). For the deposition onto the 5 layer LB film, the electrodes were reversed and the bare Pt film was used as the charged electrode and the gold film coated with the LB film was the ground electrode. In this case, the reduction of sulfur occurred at the bare platinum electrode and thus may have resulted in an increased concentration of $S^{2-}$ relative to the depositions on 3 and 4 layer LB films.

\subsection{Analysis of CdS Films}

The CdS films were examined with an atomic force microscope from Digital Instruments Inc. (model: Nanoscope II). Direct contact imaging was done both in height mode and in force mode, and both types of images are presented herein. In general, height mode images reveal information on the vertical topography of the surface of the films and was used herein to estimate the thickness of conformal films, while force mode provides sharper images of features on the surface of the films and was used in high resolution imaging.[15] For imaging at low magnifications, the scanning speed was $2.48 \mathrm{~Hz}$. No data filtering was used during scanning. The integral, proportional, and 2D gains were tuned to the highest possible values for the height mode, but the lowest possible values for the force mode.[15]

At high magnification, the AFM was used to image the crystalline lattice of the deposited CdS. For these experiments, the AFM was calibrated versus a standard mica sheet. To minimize thermal and mechanical drifts of the microscope, the scanning was performed for at least two hours before taking the image and scanning was conducted at a high speed $(39.06 \mathrm{~Hz})$ and on a relatively large area $\left(32 \times 32 \mathrm{~nm}^{2}\right)$. The force mode was used and during data collection the input, high pass, and low pass filters were off. To obtain the high resolution image of the crystalline lattice of CdS (Figure 4B), the raw data (Figure 4A) was subjected to a 2D Fourier transform and principal wave numbers thus obtained were selected and used to perform an inverse 2D Fourier transform to result in the filtered image of the crystalline lattice. 
The CdS films were also examined by optical video microscopy using a Nikon Optiphot 66 and image analysis system. Films were characterized using energy dispersive $\mathrm{X}$-ray analysis (EDAX) using an AMRAY 1500 scanning electron microscope.

\section{Results and Discussion}

We examined a variety of deposition conditions and configurations and present below a synopsis of the results from four different types of deposition experiments that demonstrate the utility of organic templates in influencing CdS film formation during electrodeposition. Table 1 lists the experimental codes and conditions for the four different types of depositions we will discuss below. Deposition conditions varied in the nature of the deposition surface examined, in deposition time, and in the magnitude of the alternating voltage used. For each deposition surface (e.g., organic template vs. noninteracting functional group), the deposition conditions for the experiments presented were those found by trial and error optimization to give rise to rapid deposition (when deposition occurred at all) of CdS films. Figure 1 shows schematic diagrams of the electrodeposition cells used in the various deposition experiments.

Table 1: Summary of the experimental conditions for the four types of electrochemical depositions.

\begin{tabular}{|c|c|c|c|c|}
\hline Experimental Codes & BARE-Au & 3-LB & 4-LB & 5-LB \\
\hline $\begin{array}{c}\text { Deposition } \\
\text { Surface }\end{array}$ & Plain Au & $\begin{array}{c}\text { Cd-carboxylate } \\
\text { (3 layer LB film }\end{array}$ & $\begin{array}{c}\text { Methyl } \\
\text { (4 layer LB film }\end{array}$ & $\begin{array}{c}\text { Cd-carboxylate } \\
\text { (5 layer LB film }\end{array}$ \\
\hline Deposition Time & 1 minute & 1 minute & 5 minutes & 5 minutes \\
\hline Voltage Cycles & $1 \mathrm{~V}, 2 \mathrm{~s} /-1 \mathrm{~V}, 1 \mathrm{~s}$ & $1 \mathrm{~V}, 2 \mathrm{~s} /-1 \mathrm{~V}, 1 \mathrm{~s}$ & $\begin{array}{c}1.75 \mathrm{~V}, 2 \mathrm{~s} / \\
-1.75 \mathrm{~V}, 1 \mathrm{~s}\end{array}$ & $2 \mathrm{~V}, 2 \mathrm{~s} /-2 \mathrm{~V}, 1 \mathrm{~s}$ \\
\hline $\begin{array}{c}\text { Electrode used for Cd } \\
\text { Deposition }\end{array}$ & Charged & Charged & Charged & Ground \\
\hline $\begin{array}{c}\text { Reducing Electrode for } \\
\mathrm{S}\end{array}$ & Plain Au & Au with SAM & Au with SAM & Plain Pt \\
\hline Results & Loose particles & $\begin{array}{c}\text { Layered single } \\
\text { crystallites with } \\
\text { crystalline } \\
\text { surfaces }\end{array}$ & $\begin{array}{c}\text { No deposition on } \\
\text { LB film }\end{array}$ & $\begin{array}{c}\text { Homogeneous } \\
\text { conformal thin } \\
\text { film }\end{array}$ \\
\hline
\end{tabular}



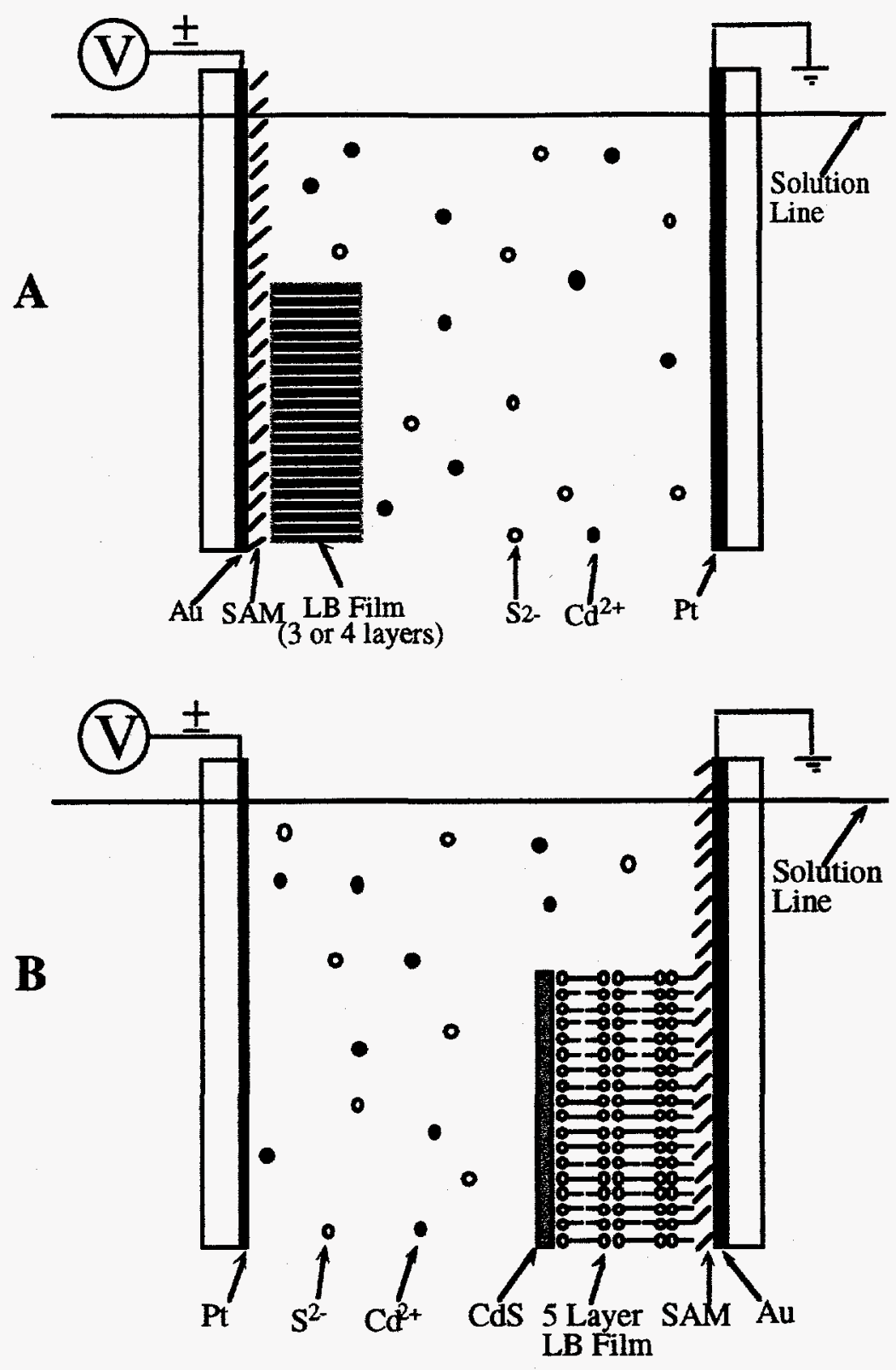

Figure 1: Schematic diagram of the electrochemical deposition cells investigated. In all depositions, the left electrode (referred to as the charged electrode) was subjected to an alternating (square wave) potential cycle relative to the ground electrode (right) to effect the deposition (see Table 1 for voltage magnitudes and durations and the total deposition times). A. Deposition cell used for the BARE-AU, 3-LB, and 4-LB experiments. For the BARE-AU experiment, no SAM or LB film was present on the left electrode. For the 3LB experiments, a 3 layer LB film, terminated with cadmium carboxylate groups, was deposited on a portion of the left gold electrode, whose entire surface had been subjected to modification by formation of a SAM of hexadecane thiolate. For the 4-LB

experiments, a 4 layer LB film, terminated with methyl groups, was deposited on the SAM-modified gold electrode. B. Deposition cell used for the 5-LB experiments. For these experiments, the gold film was used as the right (ground) electrode. The ground electrode was modified first by formation of a SAM, and then by formation of a 5 layer LB film, terminated in cadmium carboxylate groups, on a portion of the electrode surface. Note that in all cases, other ionic species (see Experimental section) were also present in the deposition solution. 


\subsection{Electrodeposition of $\mathrm{CdS}$}

Initial experiments focused on examining CdS films formed in a deposition cell similar to that used by Fatas et al. [7] We used alternating voltage cycles, and deposition times that had previously been shown by cyclic voltammetry to be sufficient for the electrolytic formation of low concentrations of $\mathrm{S}^{2-}$.[7] The basic setup for these depositions (referred to as BARE-AU), which were performed on a bare gold electrode (i.e., not modified with a SAM or an LB film) is indicated in Table 1 and in Figure 1A.

Figure 2 shows an optical micrograph of the material deposited in the BARE-AU experiment. After $1 \mathrm{~min}$, sparse amounts of material were observed to deposit on the bare gold electrode. Deposition was restricted primarily to the surface of the charged electrode, suggesting a deposition mechanism influenced by the electrochemical nature of the deposition cell. Deposited material exhibited uneven coverage of the gold surface, and when removed from solution and dryed, exhibited poor adhesion to the electrode surface. (Particles were removable from the surface by light blowing.) In the remainder of experiments, we attempted to identify deposition conditions that took advantage of the biomimetic, template-assisting qualities of carboxylate-terminated LB films for producing deposited films with superior qualities (conformal coverage, crystallinity, adhesion).[8,9]

\subsection{Template-Assisted Electrochemical Deposition of Crystalline CdS}

The first template-assisted depositions investigated (referred to as 3-LB) were ones in which the gold film used as the charged electrode was modified first by the reaction of the gold with $\mathrm{HS}\left(\mathrm{CH}_{2}\right)_{15} \mathrm{CH}_{3}$ to form a hydrophobic $\mathrm{SAM}$, and then by forming a threelayer LB film of cadmium arachidate on a portion of the electrode. This procedure resulted in a surface of exposed cadmium carboxylate groups for use as templates for nucleation of CdS (see Figure 1A). Electrochemical deposition at this modified electrode was then performed under conditions (voltage cycles, duration) similar to those used in the BAREAU deposition.

Figures 3A and 3B show optical and atomic force micrographs, respectively, of CdS deposited under the 3-LB conditions at the boundary region of the electrode between areas that were, and were not, modified with the three-layer LB film. These micrographs show that deposited material was restricted primarily to the surface of the LB film and that this material consisted of roughly evenly spaced clusters that were $\sim 1 \mu \mathrm{m}$ in lateral dimension. Analysis of this sample by energy dispersive $\mathrm{X}$-ray analysis (EDAX) suggested that the material formed on the LB film was composed of cadmium and sulfur. Elements $(\mathrm{Na}, \mathrm{Cl}$, $\mathrm{O}, \mathrm{N})$ of other ions present in the deposition solution were not detected. No cadmium or sulfur was detected on the surface of the SAM. The CdS formed on the surface of the LB film exhibited better adhesion than that produced from the BARE-AU deposition, and in general the deposition rate was higher for the template assisted deposition than for the BARE-AU deposition. These results suggest a template-mediated deposition mechanism on the surface of the LB film. 


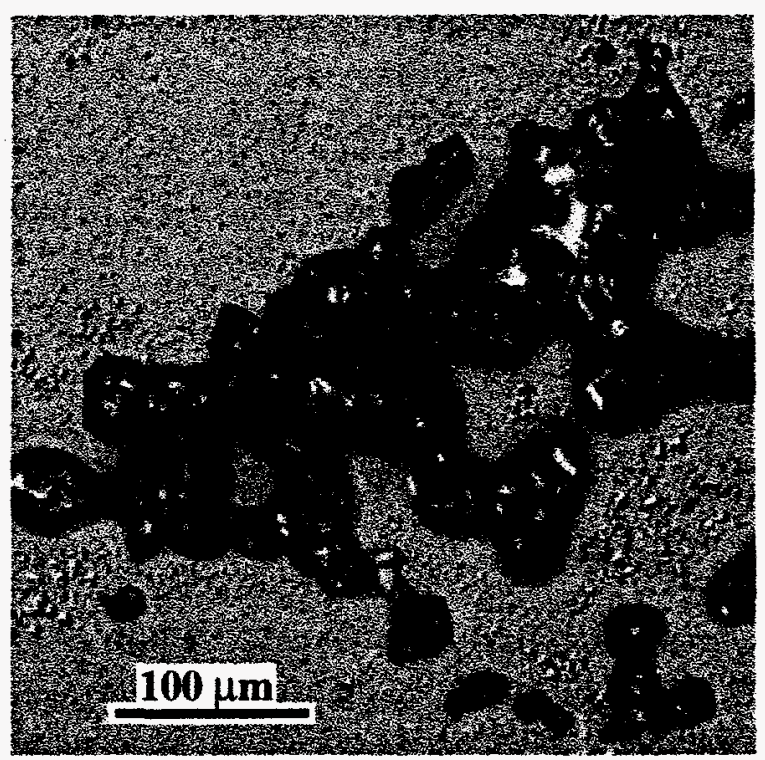

Figure 2. An optical micrograph of material deposited by electrochemical deposition. No organic template was present on the deposition surface. See Table 1 for experimental conditions (BARE-AU).

Figure $3 \mathrm{C}$ is an atomic force micrograph of a typical single particle of $\mathrm{CdS}$ formed by the 3-LB depositions. The micrograph shows that the particles formed were layered in structure and suggest that the particles were crystalline. This was later confirmed by high resolution AFM (see Figure 4 below). AFM imaging in height mode (micrograph not shown) suggested an average crystallite thickness of $\sim 30 \mathrm{~nm}$ for this sample and that the average single layer thickness was $7 \AA$. It is interesting to note that the average crystallite thickness $(30 \mathrm{~nm}$ ) and the layer thickness ( $7 \AA$ ) suggest that $\sim 40$ layers were deposited in each crystallite of CdS. This number of layers is approximately equal to twice the number of voltage cycles performed during the 1 min deposition. This result may suggest an influence of the electric field created during the voltage cycling on the deposition mechanism. We have no additional data to support this possibility at this time, however, but we plan to continue investigation of the deposition mechanism.

At this point it is important to note that, although deposition under the 3-LB experimental conditions was repeated carefully several times, the resultant films were highly variable (i.e., exhibited wide differences in deposition amount). When substantial material was indeed deposited, the micrographs shown in Figure 3 (and in Figures 4 and 5 below) are typical of the crystalline structures obtained. The high degree of variability in the results obtained for the 3-LB depositions may have been due to one or more of several factors, including variability in the number or type of defects present either in the SAM (the presumed loci for electrochemical reduction of $S$ to $S^{-2}$ ) or in the LB film. In subsequent experiments, (e.g., for the 5-LB depositions), we took measures to avoid the presence of such defects in the LB film (see below). 

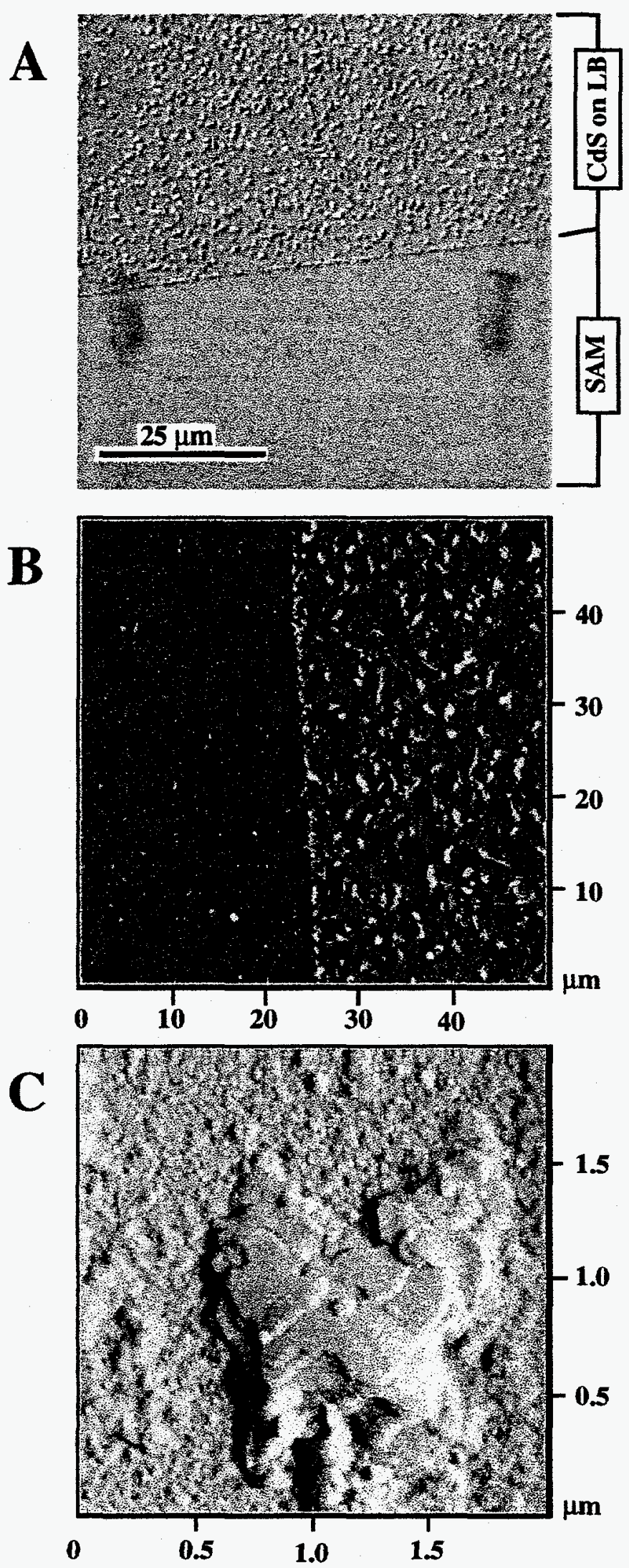

Figure 3. Optical and atomic force micrographs of $\mathrm{CdS}$ deposited by templateassisted electrochemical deposition onto a 3 layer LB film. The carboxylate groups terminating the LB film (i.e., exposed at the LB film-water interface) act as templates that mediate the CdS nucleation. See Table 1 for deposition conditions (3-LB). A. Optical micrograph of a region showing CdS deposited on LB filmmodified areas of the sample and SAM-modified areas of the sample. CdS deposition was generally restricted to the surface of the LB film. B. An atomic force micrograph (force mode imaging) of a region similar to that showed in Fig. 3A. C. An atomic force micrograph (force mode imaging, higher magnification than 3B) of an individual, layered crystallite of CdS formed on the 3 layer LB film. The background roughness observed is probably at least partially due to the structure of the surface of the gold electrode. 
Figure 4 shows a high resolution atomic force micrograph of the crystalline lattice on the surface of a typical crystallite formed in the 3-LB depositions. Fig. 4A presents the raw data (force mode) obtained through the high resolution imaging and Fig. 4B presents the image of the crystalline surface after the raw data was subjected to a Fourier transform filtering protocol.[15] When taken together with the results of the elemental analysis performed, the images obtained by high resolution AFM suggest that the deposited material is indeed crystalline CdS and that the crystals are oriented with a centered rectangular crystalline face parallel to the surface of the LB film. The centered rectangular lattice observed ( $4.67 \times 7.16 \AA$ ) is similar to that previously published for the (110) crystalline face of the greenockite polymorph of $\operatorname{CdS}(4.14 \times 7.17 \AA)$.[16] This data suggests that the template-assisted deposition conditions may be capable of producing uniformly crystalline thin films of CdS, and that the crystalline phase obtained by template-assisted electrochemical deposition may be slightly different from naturally-occuring phases.

Although the crystallite imaged in Figure 3B was typical of those observed for the 3-LB depositions, other layered and non-layered structures were also observed. Figures 5A and 5B show atomic force micrographs of another type of layered crystallite produced in the 3-LB depositions. In these crystalline structures, the primary layered structure appears not to be parallel to the electrode surface. Comparison of Figure 5A, acquired from the structure initially, to Figure 5B, taken after repeated scanning of the sample, shows the ability of the AFM tip to remove successive layers of the stratified material.

While it may be that the material imaged in Figs. 5A and 5B, has the same crystallographic structure as the CdS imaged in Figures 3 and 4, the material imaged in Fig. $5 \mathrm{C}$ appears to be a different form of $\mathrm{CdS}$, or perhaps another material entirely. The material shown in Fig. 5C constituted the most conspicuous minor component of the material deposited in the 3-LB depositions. Features with this sort of morphology, which were typically much larger than the major component shown in previous figures (compare scales in 5C with 5A and 5B), constituted less than one percent of the deposited structures. These structures showed no clear layered morphology, and we were unable to obtain a crystalline lattice upon imaging at high resolution with AFM. The fact that the vast majority of deposited crystallites were of similar size and morphology and that these other minor constituents of larger size were present at much lower concentration suggests that templateassisted deposition may be used to deposit crystalline materials with very narrow particle size distributions. 

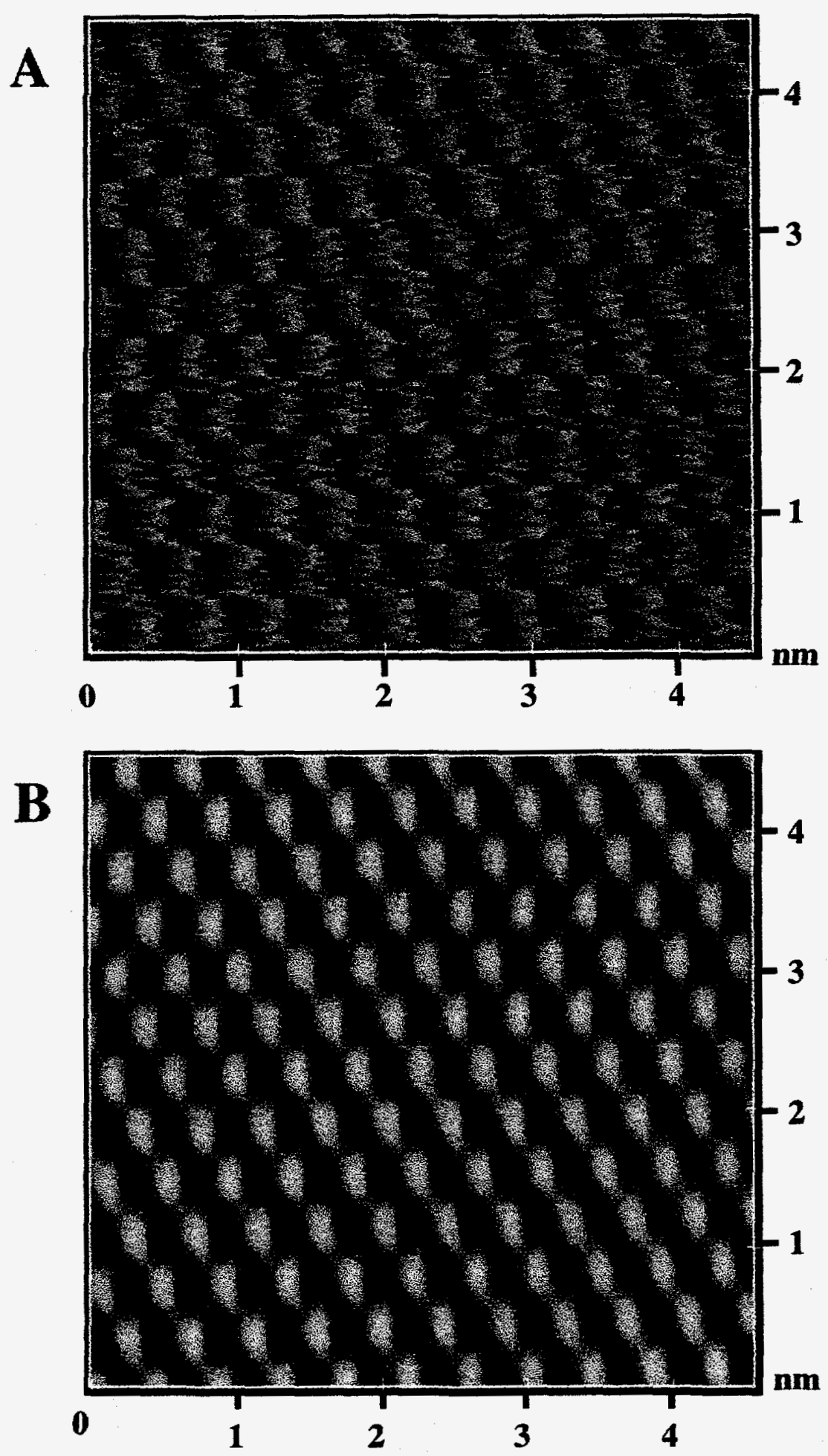

Figure 4. High resolution atomic force micrograph showing the crystalline lattice of CdS deposited on a 3 layer LB film. See Table 1 for deposition conditions (3-LB). A. Unfiltered image of the CdS lattice obtained by high resolution imaging of a crystallite such as the one shown in Fig. 3C. B. The image of the CdS crystalline lattice (same area shown in 4A) after filtering by a 2D Fourier transform filtering routine. 


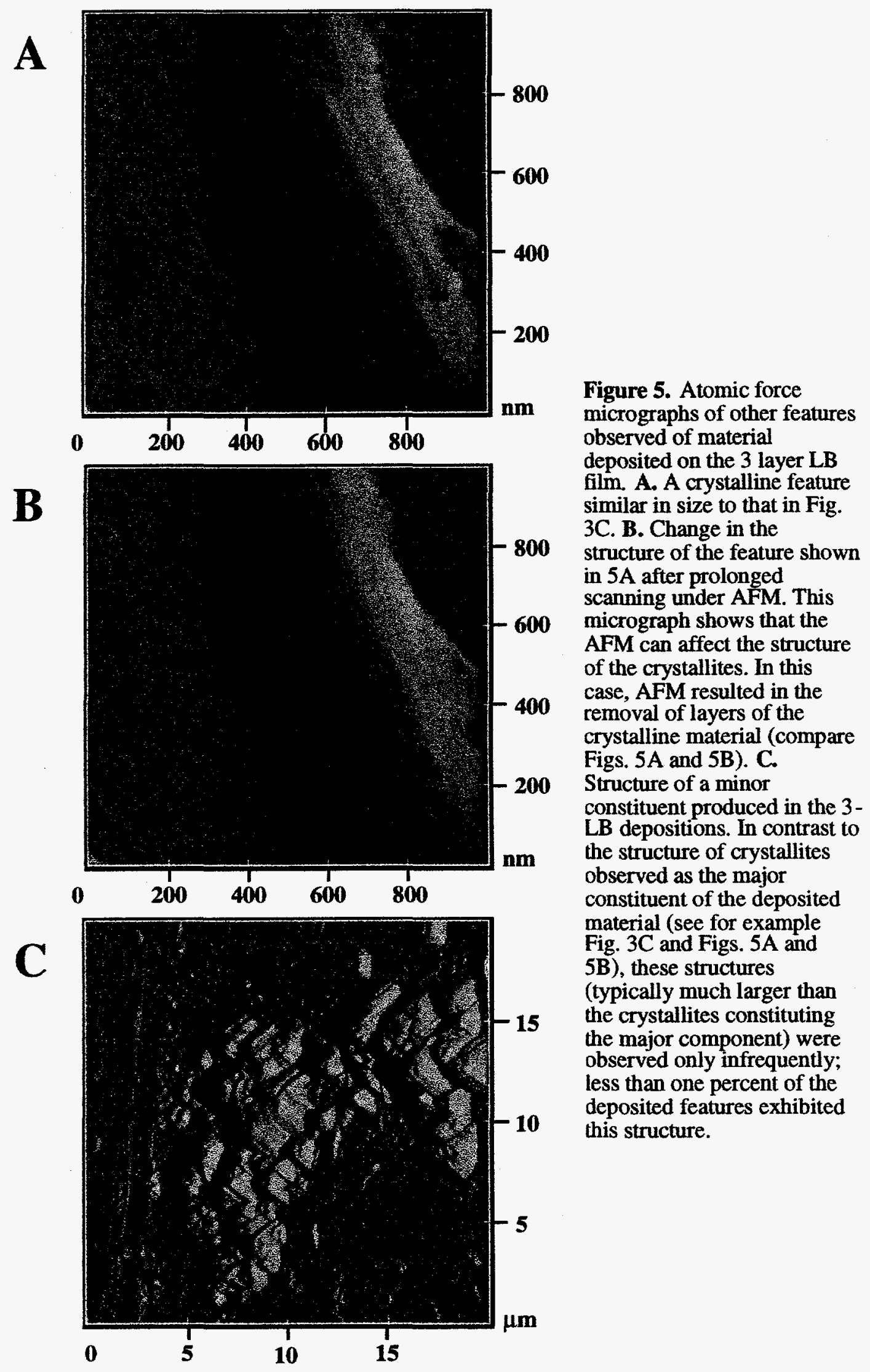

B - 12 
In order to further examine the hypothesis that the carboxylate groups on the surface of the 3-LB samples were indeed participating in template-assisted deposition, we performed an experiment (4-LB) which used deposition conditions similar to those used for the 3-LB experiments, with the exception that the charged electrode was covered with a four layer LB film. The outer surface (interfacing with the deposition solution) of this LB film is terminated in hydrophobic methyl groups. Under the conditions (voltage cycle, deposition time) used for the 3-LB depositions, no easily detectable amounts of material were formed, either on the LB film or on the SAM. Only after the amplitude of the voltage cycle $( \pm 1.75 \mathrm{~V})$ and the deposition time $(5 \mathrm{~min})$ were increased, did detectable amounts of material become deposited. Figure 6 shows an optical micrograph of the boundary region between the LB film and the SAM underlayer of such a sample after it had been subjected to the 4-LB conditions. It is clear that under similar deposition conditions to those used in the 3-LB experiment, an LB film terminated with hydrophobic methyl groups (4-LB) inhibited the crystallization of CdS. On the areas of the electrode covered with only the SAM, only sparse amounts of material were deposited, presumably at defect sites. These results when taken together with those presented above, strongly suggest a nucleation or deposition mechanism that is mediated by the carboxylate or carboxylic groups on the surface of the 3 layer LB films.

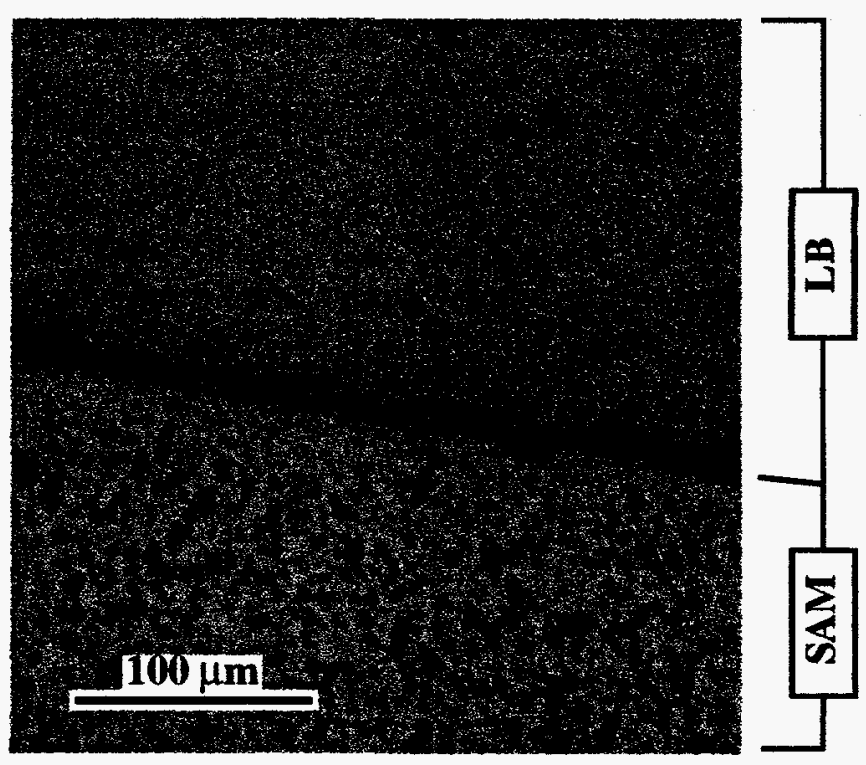

Figure 6. An optical micrograph of a portion of a 4 layer LB film (terminated in methyl groups) and a portion of a SAM after they had been subjected to conditions that produced deposition of crystalline CdS particles on 3 layer LB films. See Table 1 for deposition conditions (4-LB). 


\subsection{Conformal CdS Thin Films Produced By Template-Assisted Electrochemical Deposition.}

The final deposition conditions investigated used information gained in previous experiments to obtain uniform thin films of $\mathrm{CdS}$ by template-assisted electrochemical deposition. 5-layer LB films terminated in cadmium carboxylate groups were fabricated and used as templating surfaces. 5-layer LB films are thought to be, in general, more ordered on a molecular level than three layer films,[17] and our aim was to obtain as uniform a templating surface as possible in order to enhance uniform nucleation and crystallization of CdS.[18] The dipping conditions for forming the LB films (concentration of $\mathrm{Cd}^{2+}, \mathrm{pH}$ ) were also adjusted to values known to produce more ordered LB films (see Experimental section). Furthermore the LB films (formed on a SAM-modified Au film) were deposited onto gold electrodes that were now used as the ground electrodes in the deposition cell. A bare platinum electrode was used as the charged electrode so that reduction of $S$ to $S^{2-}$ proceeded unhindered by a dielectric SAM or LB layer. Figure 1B gives the schematic of the deposition setup for the 5-LB depositions (see also Table 1).

Figure 7 shows that, by making these changes, we were able to fabricate conformal thin films of CdS by template-assisted electrochemical deposition at relatively high deposition rates on the LB films. Furthermore, these deposition conditions (summarized in Table 1) produced a high level of reproducibility in making these thin films. Figures 7A and 7B show optical and atomic force micrographs, respectively, of the boundary region between the LB film-covered area of the electrode and the area of the electrode that was modified with only a SAM. These micrographs indicate that the amount of material deposited was much greater on the 5 layer LB film than on the hydrophobic SAM and, that uniform conformal thin films were deposited on the 5 layer LB films. EDAX suggested that the material that was deposited on the LB film was CdS, in that $\mathrm{Cd}$ and $\mathrm{S}$ were detected while no other elements $(\mathrm{Na}, \mathrm{Cl}, \mathrm{O}, \mathrm{N})$ from ions in the deposition solution were detected. AFM measurements (height mode, data not shown) of this boundary region indicated that the average thickness of the deposited film was $\sim 40 \mathrm{~nm}$.

Although the fact that the deposited material (presumably $\mathrm{CdS}$ ) was restricted primarily to the LB film area suggested a template-mediated deposition mechanism, the morphology (particle shape and surface features, see Figure 7C) of the material was different from that of the crystalline CdS deposited in the 3-LB depositions. Furthermore, we were not able to obtain an image of the crystal structure of the surface with AFM as we did for the 3-LB sample. We are currently investigating further the possible structure and the deposition mechanism of the CdS thin films obtained under the 5-LB deposition conditions. One possibility is that the higher $\mathrm{S}^{2-}$ concentration produced in the 5-LB depositions favored homogeneous nucleation of CdS and the deposited film is composed, at least in part, of crystallites nucleated in solution. These crystallites, perhaps deposited by a physical adsorption mechanism, would be less likely to have uniform crystallographic orientations than crystallites that nucleated on the underlying, ordered LB film. 

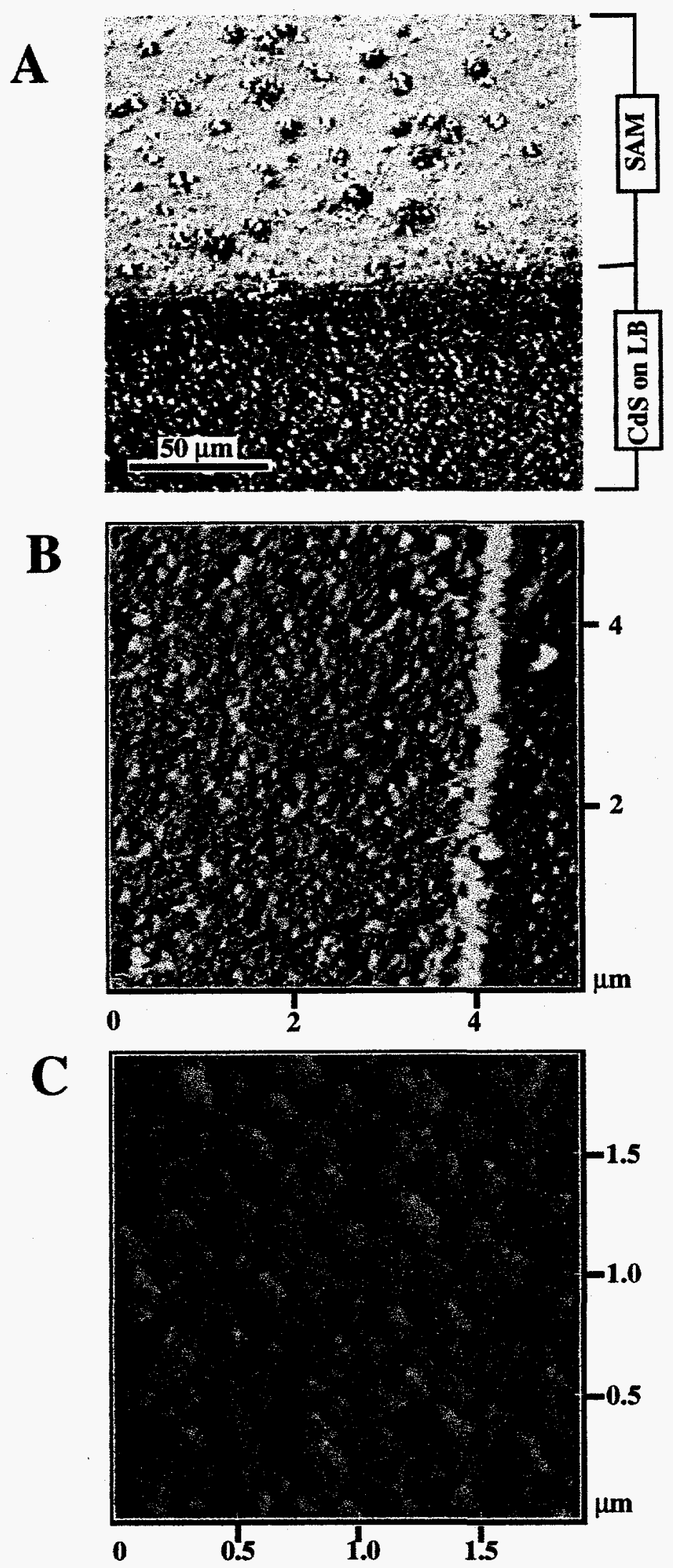

Figure 7. Optical and atomic force micrographs of a uniform thin film ( -40 am in thickness) of CdS deposited by templateassisted electrochemical deposition onto a 5 layer LB film. See Table 1 for deposition conditions (5 LB). A. Optical micrograph of a region showing CdS deposition on LB-modified areas of the sample, and SAM modified areas of the sample. CdS deposition was generally restricted to the surface of the LB film. B. An atomic force micrograph (force mode imaging) of a region similar to that shown in Fig. 7A. C. An atomic force micrograph (force mode imaging, higher magnification than 7B) of the surface of the CdS film formed on the 5 layer LB film. 


\section{Conclusions}

We have devised a method for template-assisted electrochemical deposition of CdS that produced adherent, conformal thin films with relatively fast deposition rates when compared to other solution precipitation methods. The methods described may form a route to the deposition of crystalline, uniform, thin CdS films that exhibit crystallographic orientations that are dictated by an underlying organic template where nucleation occurs.

Work is ongoing in our group to examine the mechanisms of deposition for the formation of such films. Emphasis in this work includes the investigation of possible cooperative assembly between the LB templates and the nucleated CdS crystals, and the effects of electric fields on the crystallization process. In addition, we are continuing to characterize the structures of CdS films deposited in this manner. Current efforts include analysis by transmission electron microscopy, $\mathrm{X}$-ray diffraction and atomic force microscopy.

\section{Acknowledgments}

This work was supported in part by the National Science Foundation (HRD9450475) and by the United States Department of Energy under Contract DE-AC0494AL85000. Sandia is a multiprogram laboratory operated by Sandia Corporation, a Lockheed Martin Company, for the United States Department of Energy.

\section{References}

1 P. C. Rieke, S. B. Bentjen, Chem. Mater., 5 (1993) 43.

2 Y. Fainman, J. Ma, S. H. Lee, Mater. Sci. Rep., 9 (1993) 53.

3 T. L. Chu, S. S. Chu, N. Schultz, C. Wang, C. Q. Wu, J. Electrochem. Soc., 139 (1992) 2443.

4 K. I. Grancharova, J. G. Bistrev, L. J. Bedikjan, G. B. Spasova, J. Mater. Sci. Lett., 12 (1993) 852.

5 C. Trager-Cowan, P. J. Parbrook, F. Yang, X. Chen, B. Henderson, K. P. O'Donnell, B. Cockayne, P. J. Wright, J. Cryst. Growth, 117 (1992) 532.

6 T. Miyasato, M. Tonouchi, Mater. Sci. Eng., B9 (1991) 195.

7 E. Fatas, P. Herrasti, F. Arjona, E. G. Camarero, J. Electrochem. Soc., 11 (1987) 2799.

8 B. R. Heywood, S. Mann, Adv. Mater., 6 (1994) 9.

9 E. M. Landau, S. G. Wolf, M. Levanon, L. Leiserowitz, M. Lahav, J. Sagiv, J. Am. Chem. Soc., 111 (1989) 1436.

10 Y. Tian, J. H. Fendler, Chem. Mater., 8 (1996) 969. 
11 R. S. Urquhart, C. L. Hoffmann, D. N. Furlong, N. J. Geddes, J. F. Rabolt, F. Grieser, J. Phys. Chem., 99 (1995) 15987.

12 P. Facci, V. Erokhin, A. Tronin, C. Nicolini, J. Phys. Chem., 98 (1994) 13323.

13 A. Ulman, An introduction to ultrathin organic films : from Langmuir-Blodgett to selfassembly, Boston, Academic Press, 1991

14 L. H. DuBois, R. G. Nuzzo, Ann. Rev. Phys. Chem., 43 (1992) 437.

15 Digital Instruments, Nanoscope II Scanning Probe Microscope Instruction Manual, Ver.

5, Digital Instruments, Santa Barbara (CA), 1990.

16 N. Razik, J. Mater. Sci. Lett., 6 (1987) 1443.

17 V. Skita, M. Filipkowski, A. F. Garito, J. K. Blaisie, Phy. Rev., B34 (1986) 5826.

18 S. Mann, B. R. Heywood, S. Rajam, R. J. Davey, J. D. Birchall, Nature, 334 (1988) 692. 


\title{
APPENDIX C
}

\section{Characterization of Langmuir - Blodgett Films Using X-ray Reflectivity}

\author{
J. Cesarano, D. Chen, M. Kent, D. Fein \\ Materials and Process Science Center \\ Sandia National Laboratories
}

\begin{abstract}
SUMMARY
$\mathrm{X}$-ray reflectivity is a technique that measures the intensity of scattered $\mathrm{X}$-rays that have been reflected from a surface at very small angles. This technique is very useful for determining the detailed structure of thin molecular films. However, there are limitations of this technique: 1) the structural information that is gleaned from this technique is primarily for structure throughout the thickness of the films. That is, the out-of-plane structure that is perpendicular to the substrate; 2) the structural information yields averaged information for the entire analysis area; and 3) The film structure does not come directly from the reflectivity data. An end user must guess what the actual structure may be and then use a model to calculate a reflectivity curve. If the calculated values fit the experimental data then it is assumed that the guessed structure is the actual structure. This may not be totally satisfying in that you may never be absolutely certain that there is a unique structural solution. However, in reality, the probability of having several solutions to one reflectivity curve is very low. In order to fit a reflectivity curve, four parameters must be used for each uniform layer within the structure and calculated curves vary greatly as each parameter is varied. The variables are thickness, roughness, and two parameters related to how the layer scatters $\mathrm{X}$-rays.

The work described below is for the study of Langmuir Blodgett (LB) films of $\mathrm{Cd}$-arachidate on silicon wafers. $\mathrm{Cd}$-arachidate films up to 10 layers were analyzed. The structure of the LB films is actually comprised of several layered components. The silicon wafers have a native oxide layer that is $15 \AA$ thick. The native oxide is then rendered hydrophobic by chemically attaching a self assembled monolayer of octadecyltrichlorosilane. The Cd-arachidate LB films are then applied. For detailed analysis, each layer within the structure must be analyzed sequentially. The structure of the $15 \AA$ thick native silicon oxide had to be determined first. Then, the oxide/silane together and then the oxide/silane/LB structures. Details of this work are presented in the tables and Figures below. The main contribution of this work is that it was determined that knowing the scattering information for a single molecular species was not enough to fit the reflectivity data. Individual segments within molecules had to be accounted for. With that completed, relatively good fits were obtained and detailed information for the out-of-plane structure of $\mathrm{Cd}$-arachidate on silicon was derived. In order to obtain a detailed model of the LB film, including in-plane structure, $x$-ray reflectivity should be coupled with other characterization techniques.
\end{abstract}




\section{X-ray Reflectivity}

- Detects the variation in the electron density of the specimen

- Has excellent resolution ( $1 \mathrm{~nm})$

- Is non-destructive

- Is ideal for use with thin samples such as Langmuir-Blodgett films

- The main drawback is that fitting the data is a lengthy process

\section{$X$-ray Reflectometer}

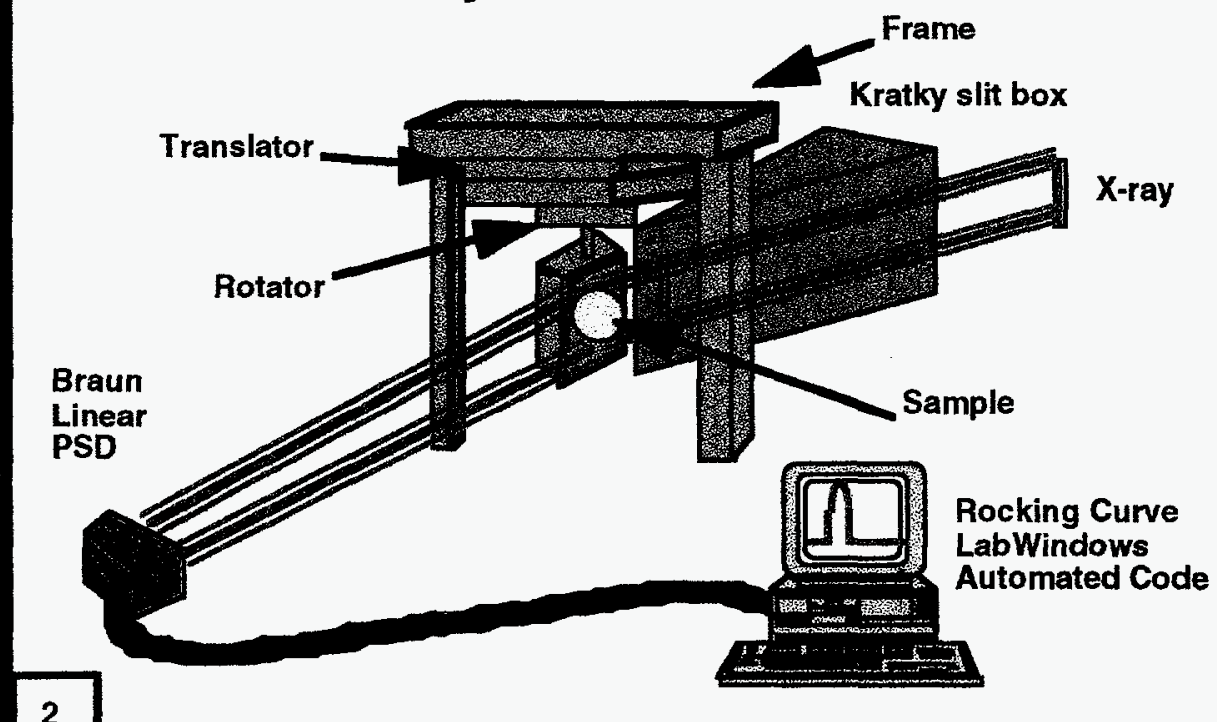




\section{Calculating Reflectivity}

- In vacuum, the $\mathrm{z}$ component of the wavevector is given by:

$$
k_{z, 0}=\left(\frac{2 \pi}{\lambda}\right) \sin \theta=Q / 2
$$

- In a medium $i$, it is given by:

$$
k_{z, i}=\left(k_{z, 0}^{2}-4 \pi p_{i}\right)^{1 / 2}
$$

Reflectlvity of a Simple Unlform FlIm

- The reflectance is given by:

$$
r_{i, i+1}=\left(k_{z, i}-k_{z, i+1}\right) /\left(k_{z, i}+k_{z, i+1}\right)
$$

- And the reflectivity is given by:

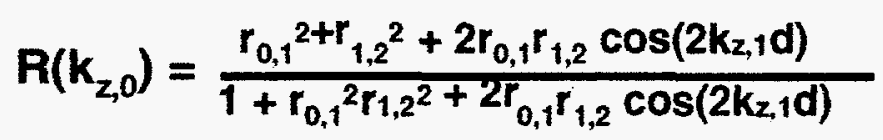




\section{Diagram of $X$-ray Path}

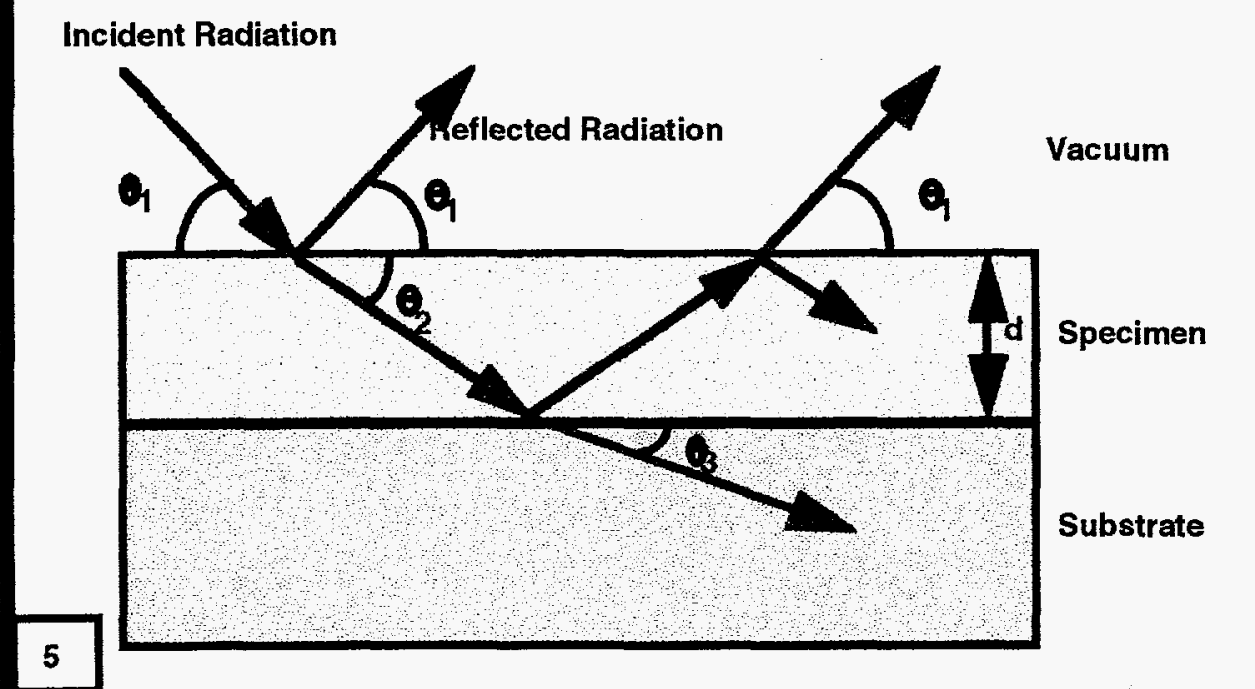

\section{For Multiple Layer Reflectivlty}

- The $x$-ray is refracted, so the incident angle is different for lower layers.

- Using Snell's Law:

$$
\begin{gathered}
n_{1} \cos \theta_{1}=n_{2} \cos \theta_{2} \\
n=\text { Refractive index } \\
n=1-\partial+i B
\end{gathered}
$$




\section{Calculation of $\partial$ and $B$}

$$
\begin{array}{cc}
\partial=\frac{\lambda^{2} p_{\text {al }} r_{0}}{2 \pi} \quad \begin{array}{l}
\lambda=\text { the wavelength of incident radiation } \\
\hat{p}_{\mathrm{ol}}=\text { the electron density } \\
\mathbf{r}_{0}=\text { the classical electron radius }
\end{array} \\
B=\frac{\mu \lambda}{4 \pi} \quad \mu=\text { the mass absorption coefficient }
\end{array}
$$

\section{Roughness}

- Roughness on a surface effectively makes the incident angle variable. This is accounted for in the theoretical calculations.

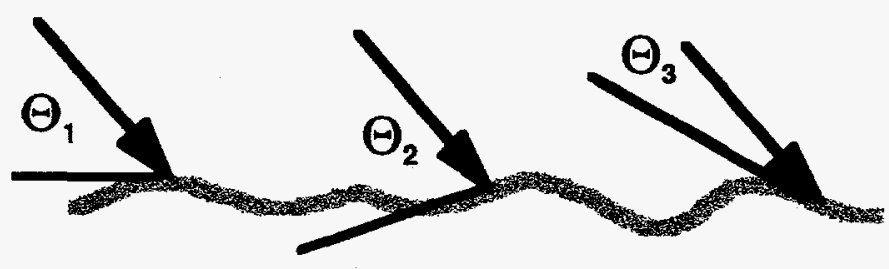




\section{Experimantal}

Preparation of Substrate(Silanation)

1) Rinse off substrate with Ethanol and DI water

2) Blow substrate dry

3) Rinse out Silanation bottles with Ethanol

4) Plasma clean substrate in Technics MICRO PD series 900 Plasma Cleaner

a) Plasma clean for about 10 to $15 \mathrm{~min}$

b) Keep at 0.250 torr and about 40 watts

5) Transfer substrate and all materials into $\left(\mathrm{N}_{2}\right)$ dry box

6) Using syringes, transfer $20 \mathrm{ml}$ of hexadecane into each bottle

7) Add $8 \mu$ l of Octadecyltrichlorosilane(OTS) to one of the bottles (concentration of OTS should be $1 \mathrm{mM}$ )

8) Transfer the substrate into the bottle with the silane-hexadecane mixture (substrate must be submerged in solution)

9) Let the reaction take place for approximately 2-4 hours

10) After the desired reaction time, transfer the substrate from the reaction mixture to the vial containing only hexadecane

11) Transfer everything out of the dry box

12) Take the sample out of the vial and rinse with Chloroform, Ethanol, and DI water. Scrub with a swab soaked in chloroform if necessary

13) Blow off sample with $\mathrm{N}_{2}$ of Ar, and store in fluoroware or plastic box

14) Dispose of waste properly

\section{Preparation of Flask that will contain subphase(Piranha Cleaning)}

1) Wear full protective clothing(long rubber apron, face mask, appropriate gloves, long pants, and shoes

2) Carefully pour 4 volumes of Sulfuric Acid into the flask

3) Slowly pour 1 volume of $30 \%$ concentrated Hydrogen Peroxide into the acid

4) While pouring the $\mathrm{H}_{2} \mathrm{O}_{2}$, gas bubbles should start to form. BE CAREFUL! This reaction is very exothermic. Be careful when you place the cap on the flask. Do not keep the cap on for a long period of time. The gas that is formed must be allowed to exit the bottle. Failure to remove the cap fast enough may result in the bottle exploding due to gas pressure

5) Place the cap on, shake the bottle, and quickly remove the cap. Repeat this for at least 15 minutes. The reaction will slow down after a while, becoming less exothermic.

6) Pour the "Pirhana solution" into the appropriate waste bottle

7) Rinse the bottle with DI water straight from the faucet for at least 5 minutes

8) The bottle is clean when the bubbles that form from shaking the bottle disappear from the water. If the bubbles stay on the surface, then the bottle still contains organic contaminants. The bottle can be used for the next 6 months without recleaning

Preparation of Subphase

1) Rinse out $2000 \mathrm{ml}$ flask with DI water straight from faucet

2) Measure out $0.1800 \mathrm{~g}$ of $\mathrm{CdCl}_{2}$ (for a Cadmium concentration of $5 \times 10^{-4} \mathrm{M}$ ) and place in the empty flask

3) Fill the flask to the top $(2000 \mathrm{ml})$ with DI water

4) Shake until the $\mathrm{CdCl}_{2}$ is dissolved and mixed thoroughly

5) Take $\mathrm{pH}$ of mixture

6) Adjust $\mathrm{pH}$ by adding $0.1 \mathrm{M} \mathrm{NaHCO} 3$ until the $\mathrm{pH}$ is about 6.50 


\section{Using the Nima Langmuir-Blodgett Trough}

Preparation of the Trough

1) The surface of the trough, and all the parts of the trough which will be in contact with the subphase should be wiped with a Kimwipe soaked in isopropanol(wearing polyethylene gloves)

2) The trough should now be wiped with a Kimwipe soaked in DI water

3) The barriers should be attached, with the end of the barrier touching the outside edge of the trough

4) The pressure sensor is then attached. Take an " $S$ " hook, and hook it to the pressure sensor wire. Attach the long copper colored wire to the other end, and attach another "S" hook to the other end of the copper wire. Then attach the Wilhelmy plate to the other end of the "S" hook

5) The subphase should then be poured into the trough. The surface of the subphase should be about 1-2mm over the top of the edge of the trough

Cleaning the Subphase

1) Before the Wilhelmy plate is lowered into the subphase, the surface should be cleaned

a) Turn on the aspirator pump

b) Put the pipette head at the surface of the subphase to suck off any floating material

c) Move the pipette around to cover the whole area between the barriers

2) Lower the Wilhelmy plate completely into the subphase and let it sit for a few minutes

3) Make sure the barriers are fully opened, and position the pressure sensor so that about two-thirds of it is submerged in the subphase

4) Zero the pressure sensor(press the $[\mathrm{Z}]$ button)

5) Lift the pressure sensor out of the subphase. The pressure should change about $70 \mathrm{mN} / \mathrm{m}$ ( the exact value for pure water in an atmosphere of saturated water vapor at $293 \mathrm{~K}$ is $72.8 \mathrm{mN} / \mathrm{m}$ )

6) Reposition and rezero the sensor

7) Press the [ENTER] button to start the isotherm. The isotherm should be constant except for a small peak at the end, caused by contaminants on the subphase surface

8) Suck off the surface of the subphase again, and open the barriers

9) Repeat steps 8 and 7 and 8 until the pressure $(\pi \mathrm{a})$ is less than $0.5 \mathrm{mN} / \mathrm{m}$ when the barriers are closed

10) If the subphase level is too low, pour more in until the level is high enough

11) Check the pressure again

12) Open the barriers completely

Spreading the Monolayer

1) Rinse out a $100 \mu$ l syringe with chloroform about 3 times

2) Get about $100 \mu$ l of Arachidic Acid in Chloroform( $2 \mathrm{mM} \sim 25 \mathrm{mg} / 40 \mathrm{ml}$ )

3) Hold the syringe tip about 5-10 mm from the surface of the subphase

4) Place one drop of the Arachidic Acid on the surface of the subphase

5) Wait for the drop to completely disappear, and repeat until all $100 \mu l$ are deposited on the surface

6) Repeat steps 2 through 5 until about $300 \mu$ l of the Arachidic Acid solution is deposited on the surface

7) Let the chloroform evaporate for at least 15 minutes. 
Dipping the Sample

1) Place the substrate in the holder, and place the holder on the trough

2) Lower the substrate until it is very close to the surface of the subphase

a) Press [D] to move the dipper

b) Press [D] again to tell the dipper to go down

c) Let the dipper lower

d)Press [SPACE BAR] to stop the dipper

3) Program the dipper

a) Press [M] to go to the menu

b) Program dipping conditions

1: Press [D] to go to the dipper menu

2: Press [A] to set the area of the substrate

3: Press [N] to set the number of layers to be dipped

4: Press [T] to set the target pressure $(28 \mathrm{mN} / \mathrm{m})$

5: Press [D] to set the dipping speed $(1.6 \mathrm{~mm} / \mathrm{min})$

6: Press [W] to set the dipper wait (Use $\sim 60 \mathrm{~s}$ )

A) This tells the dipper what duration to wait between each bilayer

B) If no wait is desired, leave it at $0 s$

7: Set dipper start and end

A) Press [E] to switch from enter to teach mode

B) Press [1], and the location of the dipper currently will appear

1- Press [SPACE BAR]

2-Press [Y] to log the position as the start position

C) Press [E] to switch back to enter mode

D) Press [2] and enter the end position

8: Press [Q] to exit dipping menu

c) Program operating conditions

1: Press [V] and enter the volume of Arachidic Acid solution used

2: Press $[B]$ to change barrier speed

3: Add any comments

4: Press [Q] to exit the operating conditions menu

d) Press [Q] to return to the isotherm

4) Cover the trough opening with the plastic sheet

5) Zero the pressure sensor(Press [Z])

6) Press [ENTER] to start the compression of the monolayer

7) When the pressure is close to the target pressure, hit [SPACE BAR]

8) Press [P] to turn on the pressure control, and press [ENTER] to compress the barriers

9) When the target pressure is reached, hit [D] to begin the dipping program

10) When the dipping is done, raise the dipper all the way

11) Remove the holder, and remove the sample. Place the sample in a plastic sample box

12) Press [S] to save data

Emptying the Trough

1) Open the barriers completely (Press [O])

2) Plug in the aspirator pump

3) Suck off the surface of the subphase

4) Press [E] to begin easy clean

a) The barriers will compress to the target pressure, and the

5) Suck out all the subphase

6) Remove the pressure sensor, and the barriers

7) Wipe the surface with kimwipes soaked in isopropanol and DI water

8) Put on trough cover and close doors

9) Press [Q] to quit the trough program

10) Turn off the computer and the trough 


\section{Sample conditions for figures}

Fig. $9 \mathrm{Si} / \mathrm{SiO}_{2} 15 \AA$

Rinsed with Ethanol and DI water

Plasma Cleaned

Substrate dimensions $=1{ }^{\prime} \mathbf{x} \mathbf{1}^{\prime}$

Fig. $10 \mathrm{Si} / \mathrm{SiO}_{2} 15 \AA$ with 1 layer of Octadecyltrichlorosilane

Rinsed with Ethanol and DI water

Plasma Cleaned

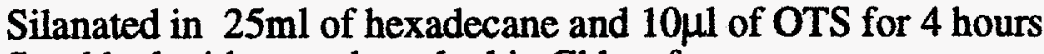

Scrubbed with a swab soaked in Chloroform

Rinsed with Chloroform, Ethanol, and DI water

Substrate dimensions $=1$ ' $x 1$ '

Fig. $11 \mathrm{Si} / \mathrm{SiO}_{2} 15 \AA$ with 1 layer of OTS and a 2 layer LB film of cadmium arachidate

Rinsed with Ethanol and DI water

Plasma Cleaned

Silanated in $20 \mathrm{ml}$ of hexadecane and $8 \mu \mathrm{l}$ of OTS for 4 hours

Scrubbed with a swab soaked in Chloroform

Rinsed with Chloroform, Ethanol, and DI water

Dipped diagonally using alligator clip holding the corner

Subphase conditions $-0.180 \mathrm{~g} \mathrm{CdCl}$, adding $\sim 1.5 \mathrm{ml}$ of

Dipper speed $=1.6 \mathrm{~mm} / \mathrm{min}$

$$
0.1 \mathrm{M} \mathrm{NaHCO}_{3} \quad \mathrm{pH}=6.49\left[\mathrm{Cd}^{++}\right]=5 \times 10^{-4} \mathrm{M}
$$

Target pressure $=28 \mathrm{mN} / \mathrm{m}$

Barrier Speed $=50 \mathrm{~cm}^{2} / \mathrm{min}$

$285 \mu 1$ of Arachidic Acid/Chloroform solution(2mM) deposited on surface

Dipper wait $=0$ seconds

Dipper start position $=24.6 \mathrm{~mm}$

Dipper end position $=55.0 \mathrm{~mm}$

Length of film $\sim 30.0 \mathrm{~mm}$

Substrate dimensions $=1^{\prime} \mathbf{x} 1^{\prime}$

Fig. $13 \mathrm{Si} / \mathrm{SiO}_{2} 15 \AA$ with 1 layer of $\mathrm{OTS}$ and a 10 layer $\mathrm{LB}$ film of $\mathrm{Cd}$-arachidate Rinsed with Ethanol and DI water

Plasma leaned

Silanated in $30 \mathrm{ml}$ of hexadecane and $12 \mu \mathrm{l}$ of OTS for 4 hours

Scrubbed with a swab soaked in Chloroform

Rinsed with Chloroform, Ethanol, and DI water

Subphase conditions $-0.180 \mathrm{~g} \mathrm{CdCl} 2$, adding $\sim 1.5 \mathrm{ml}$ of

Dipper speed $=1.6 \mathrm{~mm} / \mathrm{min}$

$$
\mathrm{pH}=6.53 \quad\left[\mathrm{Cd}^{++}\right]=5 \times 10^{-4} \mathrm{M}
$$

Target pressure $=28 \mathrm{mN} / \mathrm{m}$

Barrier Speed $=50 \mathrm{~cm}^{2} / \mathrm{min}$

$285 \mu 1$ of Arachidic Acid/Chloroform solution( $2 \mathrm{mM}$ ) deposited on surface

Dipper wait $=60$ seconds

Dipper start position $=40 \mathrm{~mm}$

Dipper end position $=74 \mathrm{~mm}$

Length of film $\sim 34 \mathrm{~mm}$

Substrate dimensions $=1$ 'x 1.5 


\begin{tabular}{|r|r|c|c|c|}
\hline Thickness $\AA$ & Delta & Beta & Roughness $\AA$ & \\
\hline 0 & 7.4 & 0.173 & 3 & silicon substrate \\
\hline 15 & 7.5 & 0.098 & 4 & silica \\
\hline
\end{tabular}

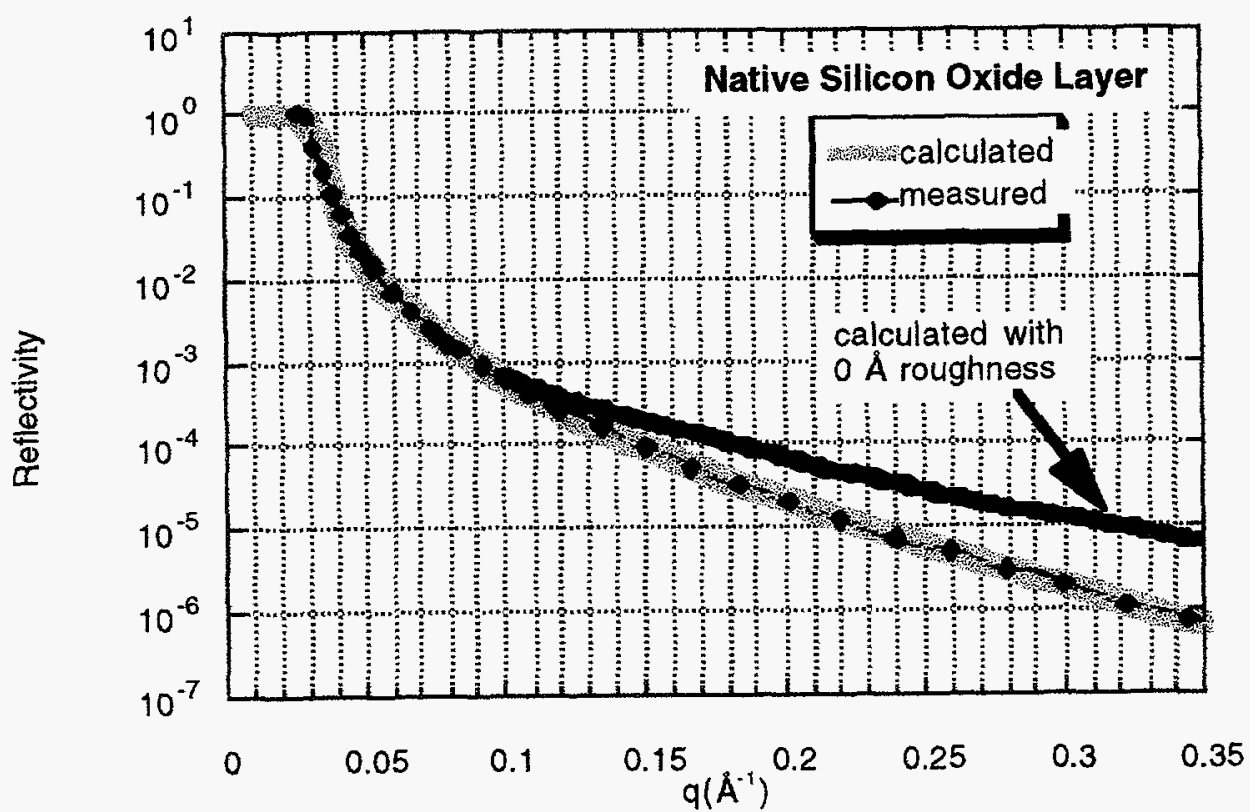

Figure 9: Reflectivity data and fit show that the native oxide layer on our silicon wafers is $15 \AA$ thick with a roughness of $4 \AA$. A roughness value $4 \AA$ was necessary to abtain a good fit with the experimaental data. 


\begin{tabular}{|r|c|c|c|c|}
\hline Th. $(\mathcal{A})$ & Delta $\times 10^{-6}$ & Beta $\times 10^{-6}$ & $R(\hat{\AA})$ & \\
\hline 0 & 7.5 & .173 & 3 & silicon substrate \\
\hline 15 & 7.5 & .098 & 4 & silica \\
\hline 5.5 & 4.22 & .1585 & 1 & silane head groups \\
\hline 15.2 & 3.48 & .00431 & 5 & hydrocarbon tail \\
\hline 1.0 & .445 & .00004 & 0 & silane H group \\
\hline
\end{tabular}

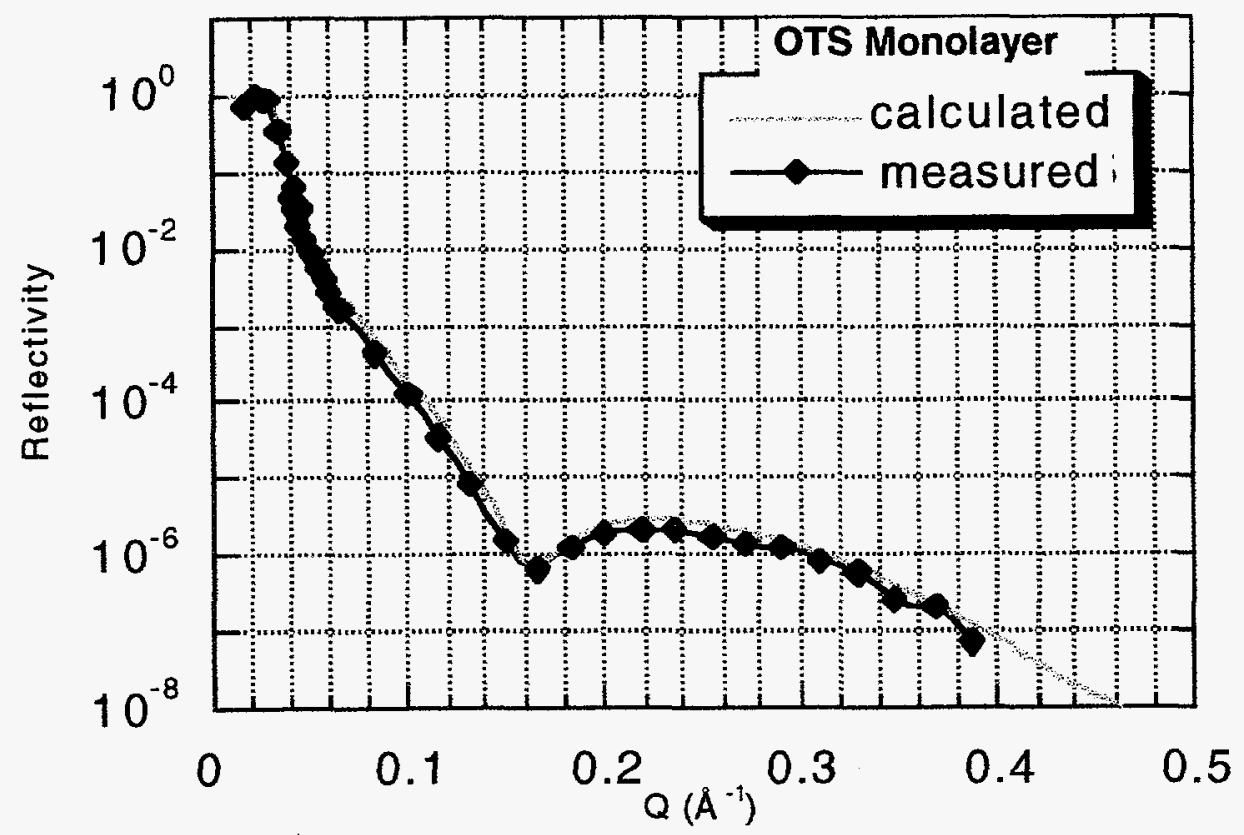

Figure 10: This reflectivity data and fit show that the OTS monolayer is conformal to the substrate with a roughness of $5 \AA$. Also, this fit shows that OTS molecules need to be anaylzed as three entities. 


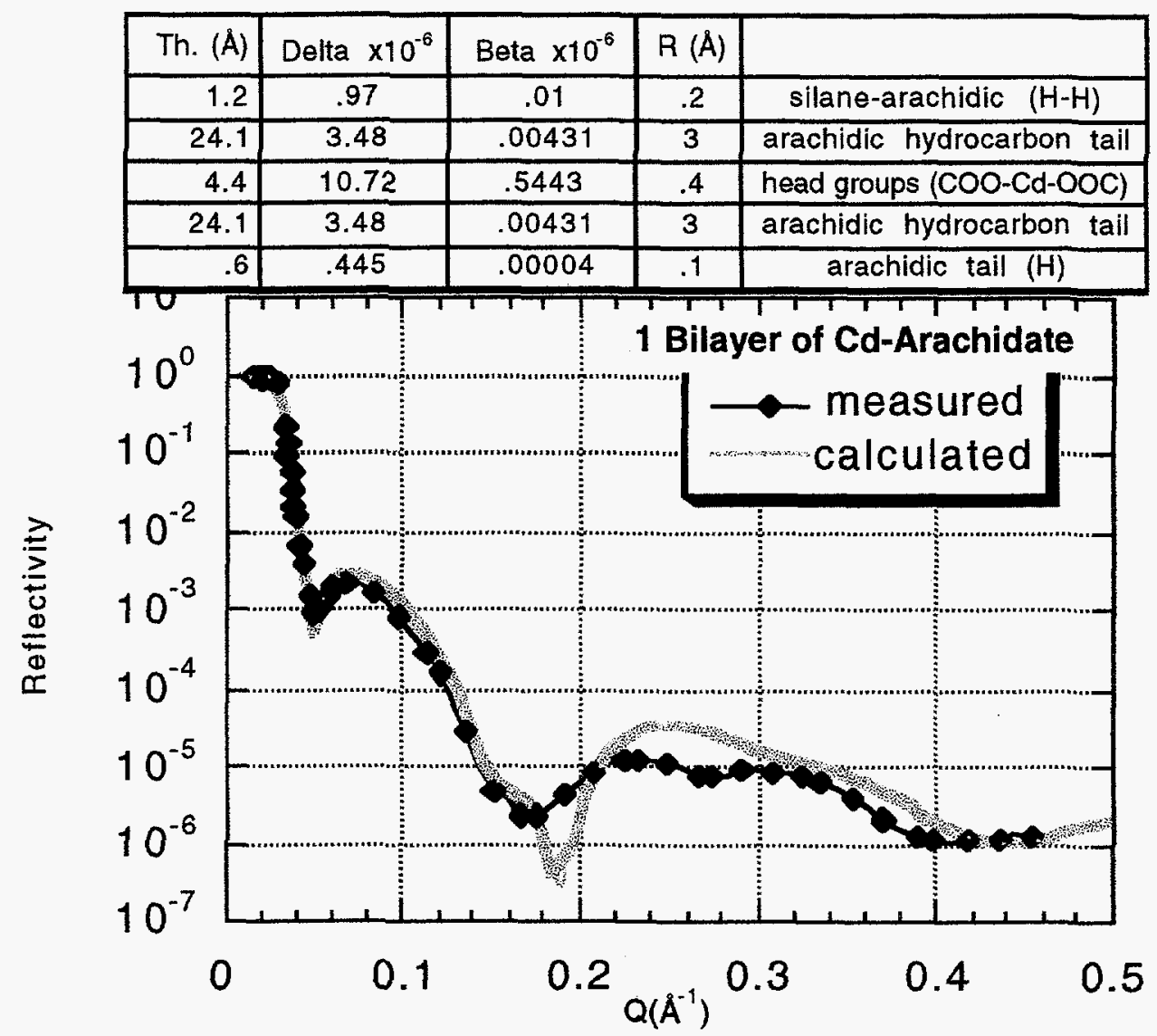

Figure 11: Reflectivity for one LB bilayer of Cd-arachidate. The fit is reasonable and shows that the bilayer is tilted about 15 degrees (see Figure 12). However the calculated structure shows more detail than the actual structure and implies that the bilayer is not as ordered as depicted in Figure 12. 


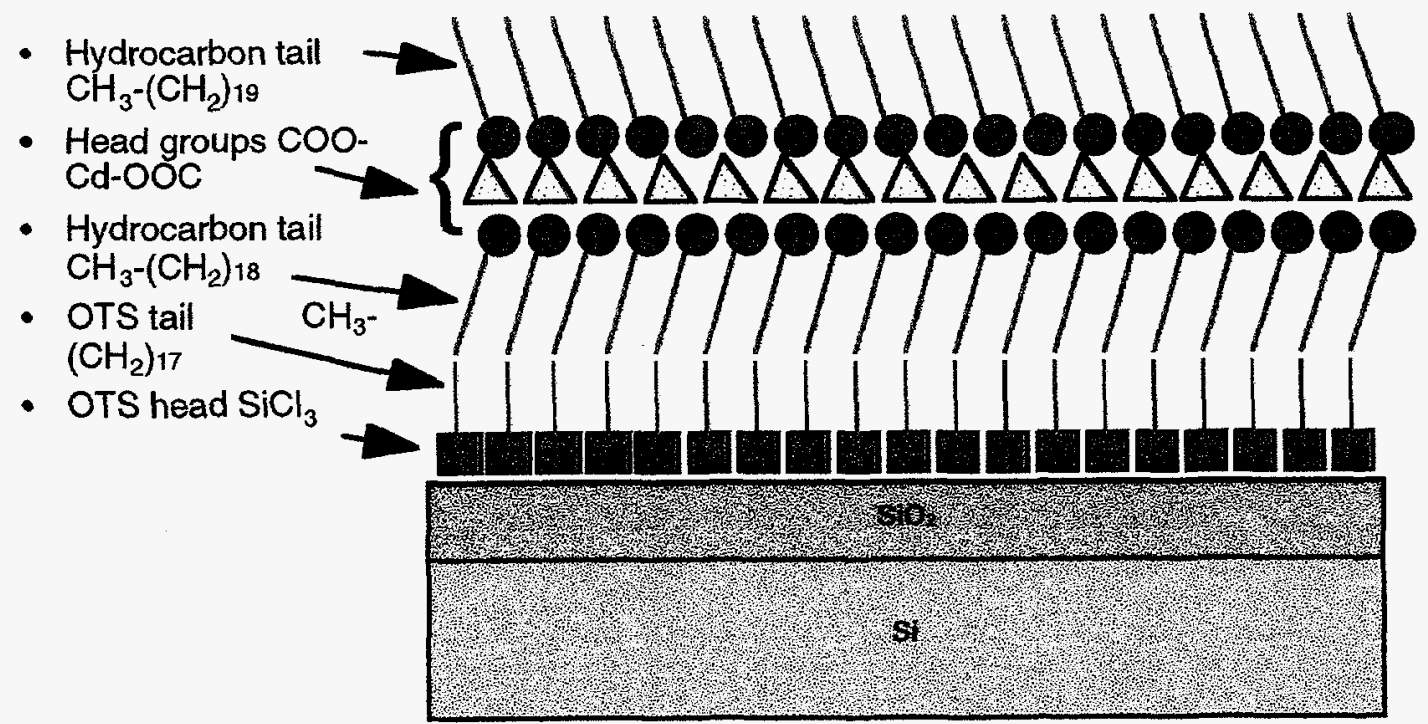

Figure 12: A schematic of the structure that was used to fit the data in Fig. 11. This fit shows that the Cd head group region must be treated separately from the rest of the bilayer. Also, the length of the hydrocarbon tails used to fit the data $(24.1 \AA)$ implies that the tails are actually tilted approximately 15 degrees from vertical. 


\section{Bilayers of $\mathrm{Cd}$-Arachidate}

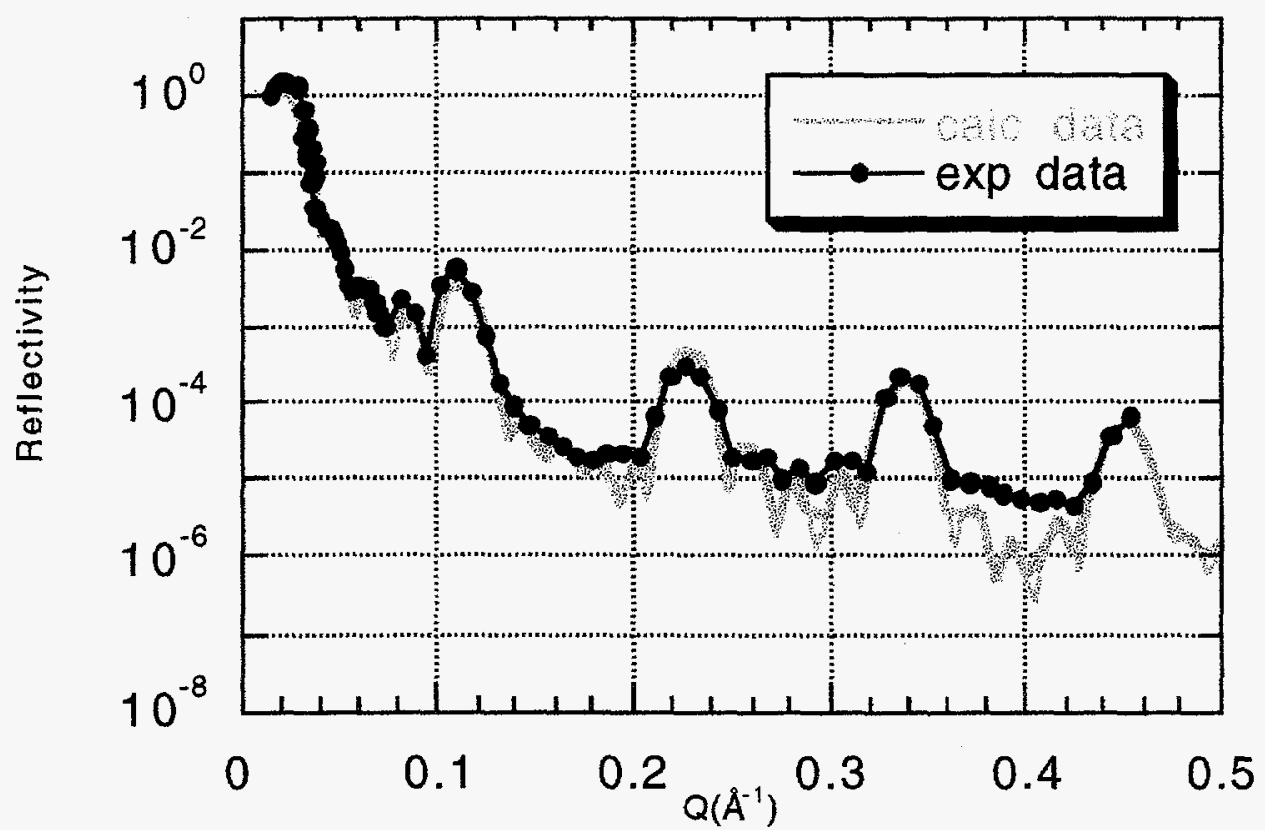

Figure 13: Reflectivity from 5 bilayers of $\mathrm{Cd}$-arachidate. The actual structure does not have the very fine detail of the fitted model structure (see Fig. 14). However, the fit and hydrocarbon tail length, imply that the LB structure is a rigid crystalline structure that is not tilted. This may explain why 5 layer $\mathrm{Cd}$-arachidate films provided better templating for $\mathrm{CdS}$ growth than the 3 layer Cd-arachidate films discussed in Appendix B. 


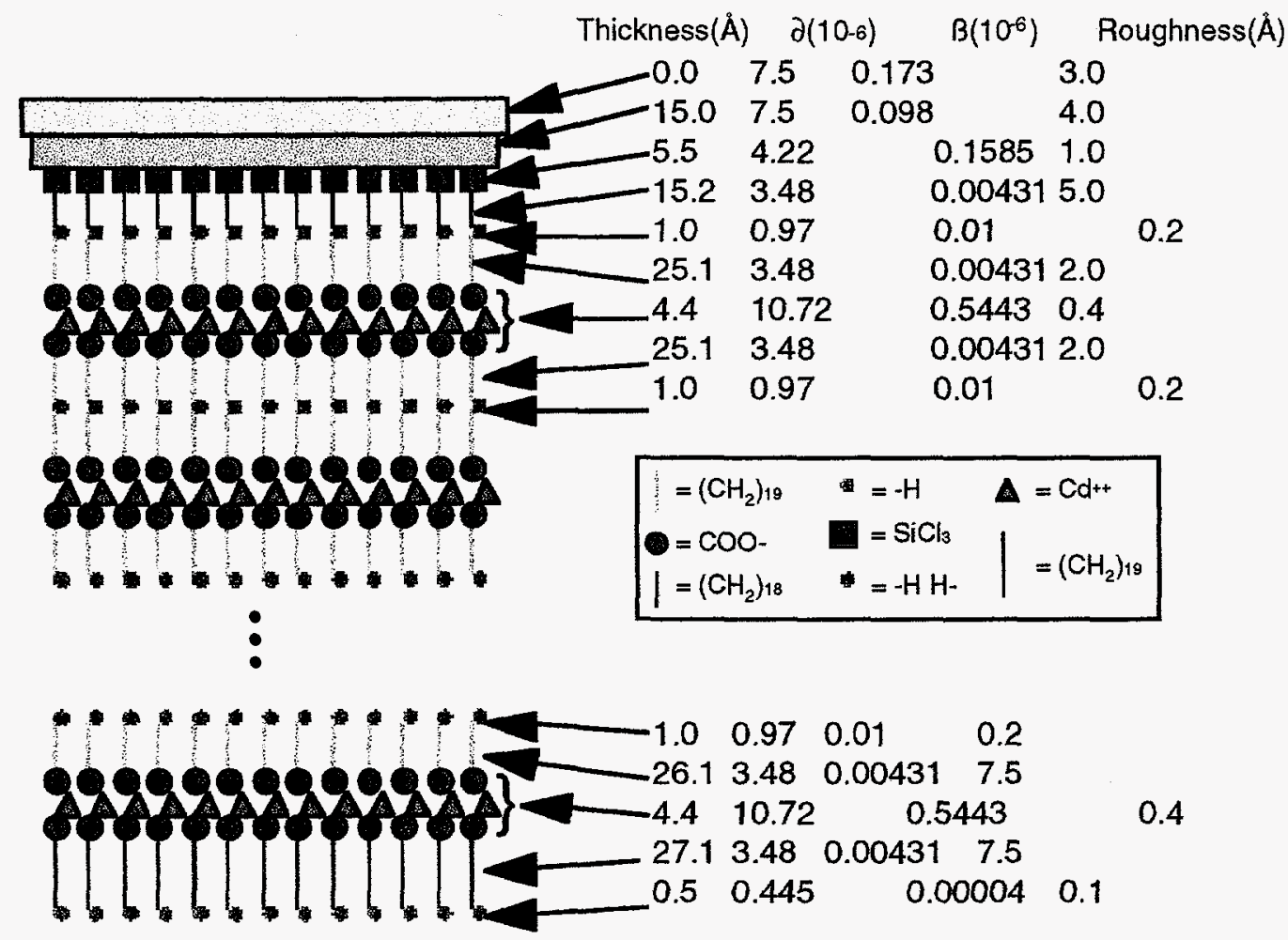

Figure 14: A schematic of the structure used to fit the reflectivity data in Fig. 13. The structure is not tilted with a bilayer thickness that is comparable to crystalline Cd-arachidate. The expected bilayer thickness for Cd-arachidate is approximateky $56 \AA$. Bilayers \#1-4 yield a thickness of $55.6 \AA+1-1 \AA$. Bilayer \#5 yields a thickness of $58.6 \AA+1-4 \AA$.

\section{References}

Russell, T.P. (1990) "X-ray and neutron reflectivity for the investigation of polymers" Materials Science Reports 5 pp. 171-271

Stanglmeier, F., Lengeler, B., Weber, W., Gobel, H. \& Schuster, M. (1992). Acta Cryst. A48, 626-639 


\section{DISTRIBUTION:}

5 MS-1349 J. Cesarano

1 MS-1407 M. Kent

1 MS-1407 D. Fein

1 MS-0860 R. J. Simonson

1 MS-1411 D. Dimos

1 MS-0333 A. Hurd

1 Gabriel Lopez

Chem. \& Nuc. Eng.

Ferris Eng. Center / Rm 209

University of New Mexico

Albuquerque, NM 87131

1 MS- 9018 Central Technical Files, 8940-2

5 MS-0899 Technical Library, 4916

2 MS-0619 Review \& Approval Desk, 12690

For DOE/OSTI

1 MS-0161 Patent and Licensing Office, 11500 